Cochrane Database of Systematic Reviews

\title{
Pulmonary artery catheters for adult patients in intensive care
} (Review)

Rajaram SS, Desai NK, Kalra A, Gajera M, Cavanaugh SK, Brampton W, Young D, Harvey S, Rowan $\mathrm{K}$

Rajaram SS, Desai NK, Kalra A, Gajera M, Cavanaugh SK, Brampton W, Young D, Harvey S, Rowan K.

Pulmonary artery catheters for adult patients in intensive care.

Cochrane Database of Systematic Reviews 2013, Issue 2. Art. No.: CD003408.

DOI: 10.1002/14651858.CD003408.pub3.

www.cochranelibrary.com 
TABLE OF CONTENTS

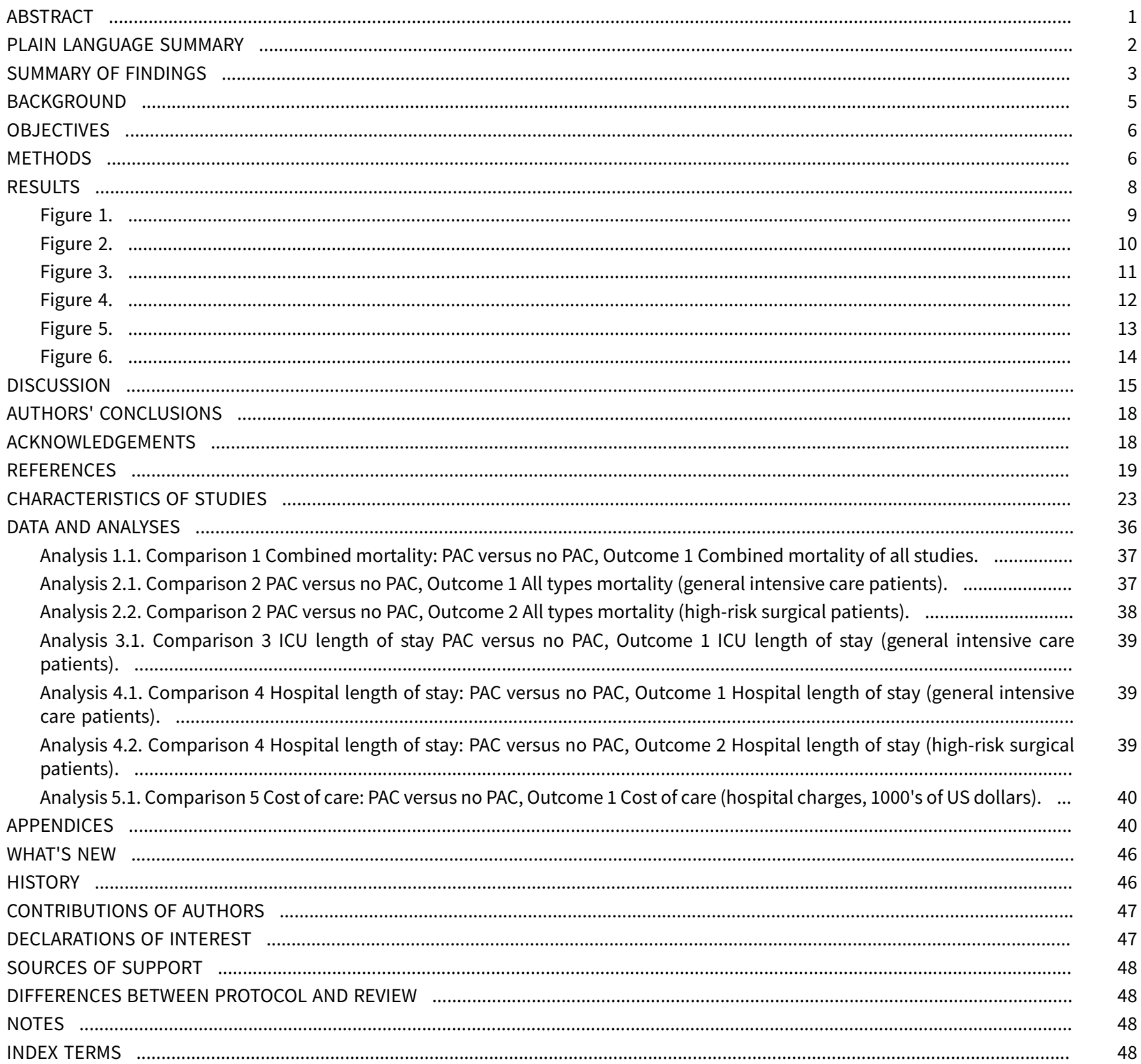


[Intervention Review]

\section{Pulmonary artery catheters for adult patients in intensive care}

Sujanthy S Rajaram ${ }^{1}$, Nayan K Desai², Ankur Kalra ${ }^{3}$, Mithil Gajera ${ }^{4}$, Susan K Cavanaugh ${ }^{5}$, William Brampton ${ }^{6}$, Duncan Young7, Sheila Harvey 8 , Kathy Rowan 8

1Department of Medicine, Hackensack University Medical Center, Hackensack, NJ, USA. 2Department of Medicine, Cooper Medical School of Rowan University (CMSRU) and UMDNJ/RWJ Medical School, Cooper University Hospital, Camden, NJ, USA. ${ }^{3}$ Section of Cardiovascular Medicine, Minneapolis Heart Institute at Abbott Northwestern Hospital/Hennepin County Medical Center, Minneapolis, MN, USA. ${ }^{4}$ Department of Medicine, Christiana Care Health System, Newark, DE, USA. ${ }^{5}$ Medical Library, Cooper University Hospital, CMSRU, Camden, NJ, USA. ${ }^{6}$ Department of Anaesthetics, Aberdeen Royal Infirmary, Aberdeen, UK. ${ }^{7}$ Adult Intensive Care Unit, John Radcliffe Hospital, Oxford, UK. 8Intensive Care National Audit \& Research Centre, London, UK

Contact: Sujanthy S Rajaram, Department of Medicine, Hackensack University Medical Center, 30, Prospect Avenue, Hackensack, NJ, 07601, USA.sujanty@gmail.com.

Editorial group: Cochrane Emergency and Critical Care Group.

Publication status and date: Edited (no change to conclusions), published in Issue 12, 2018.

Citation: Rajaram SS, Desai NK, Kalra A, Gajera M, Cavanaugh SK, Brampton W, Young D, Harvey S, Rowan K. Pulmonary artery catheters for adult patients in intensive care. Cochrane Database of Systematic Reviews 2013, Issue 2. Art. No.: CD003408. DOI: 10.1002/14651858.CD003408.pub3.

Copyright @ 2018 The Cochrane Collaboration. Published by John Wiley \& Sons, Ltd.

\section{A B S T R A C T}

\section{Background}

Since pulmonary artery balloon flotation catheterization was first introduced in 1970, by HJ Swan and W Ganz, it has been widely disseminated as a diagnostic tool without rigorous evaluation of its clinical utility and effectiveness in critically ill patients. A pulmonary artery catheter (PAC) is inserted through a central venous access into the right side of the heart and floated into the pulmonary artery. PAC is used to measure stroke volume, cardiac output, mixed venous oxygen saturation and intracardiac pressures with a variety of additional calculated variables to guide diagnosis and treatment. Complications of the procedure are mainly related to line insertion. Relatively uncommon complications include cardiac arrhythmias, pulmonary haemorrhage and infarct, and associated mortality from balloon tip rupture.

\section{Objectives}

To provide an up-to-date assessment of the effectiveness of a PAC on mortality, length of stay (LOS) in intensive care unit (ICU) and hospital and cost of care in adult intensive care patients.

\section{Search methods}

We searched the Cochrane Central Register of Controlled Trials (CENTRAL) (The Cochrane Library 2011, Issue 12); MEDLINE (1954 to January 2012); EMBASE (1980 to January 2012); CINAHL (1982 to January 2012), and reference lists of articles. We contacted researchers in the field. We did a grey literature search for articles published until January 2012.

\section{Selection criteria}

We included all randomized controlled trials conducted in adults ICUs, comparing management with and without a PAC.

\section{Data collection and analysis}

We screened the titles and abstracts and then the full text reports identified from our electronic search. Two authors (SR and MG) independently reviewed the titles, abstracts and then the full text reports for inclusion. We determined the final list of included studies by discussion among the group members (SR, ND, MG, AK and SC) with consensus agreement. We included all the studies that were in the original review. We assessed seven domains of potential risk of bias for the included studies. We examined the clinical, methodological

Pulmonary artery catheters for adult patients in intensive care (Review) 
and statistical heterogeneity and used random-effects model for meta-analysis. We calculated risk ratio for mortality across studies and mean days for LOS.

\section{Main results}

We included 13 studies (5686 patients). We judged blinding of participants and personnel and blinding of outcome assessment to be at high risk in about $50 \%$ of the included studies and at low risk in $25 \%$ to $30 \%$ of the studies. Regardless of the high risk of performance bias these studies were included based on the low weight the studies had in the meta-analysis. We rated $75 \%$ of the studies as low risk for selection, attrition and reporting bias. All 13 studies reported some type of hospital mortality (28-day, 30-day, 60-day or ICU mortality). We considered studies of high-risk surgery patients (eight studies) and general intensive care patients (five studies) separately as subgroups for meta-analysis. The pooled risk ratio (RR) for mortality for the studies of general intensive care patients was 1.02 ( $95 \%$ confidence interval (CI) 0.96 to 1.09 ) and for the studies of high-risk surgery patients the RR was 0.98 ( $95 \% \mathrm{Cl} 0.74$ to 1.29$)$. Of the eight studies of high-risk surgery patients, five evaluated the effectiveness of pre-operative optimization but there was no difference in mortality when these studies were examined separately. PAC did not affect general ICU LOS (reported by four studies) or hospital LOS (reported by nine studies). Four studies, conducted in the United States (US), reported costs based on hospital charges billed, which on average were higher in the PAC groups. Two of these studies qualified for analysis and did not show a statistically significant hospital cost difference (mean difference USD $900,95 \% \mathrm{Cl}-2620$ to $4420, \mathrm{P}=0.62)$.

\section{Authors' conclusions}

PAC is a diagnostic and haemodynamic monitoring tool but not a therapeutic intervention. Our review concluded that use of a PAC did not alter the mortality, general ICU or hospital LOS, or cost for adult patients in intensive care. The quality of evidence was high for mortality and LOS but low for cost analysis. Efficacy studies are needed to determine if there are optimal PAC-guided management protocols, which when applied to specific patient groups in ICUs could result in benefits such as shock reversal, improved organ function and less vasopressor use. Newer, less-invasive haemodynamic monitoring tools need to be validated against PAC prior to clinical use in critically ill patients.

\section{PLAIN LANGUAGE SUMMARY}

\section{Pulmonary artery catheters for adult patients in intensive care}

A pulmonary artery catheter (PAC) is a device utilized in intensive care units (ICU) to measure the pressures in the heart and lung blood vessels and to monitor patients. The catheter is inserted into the right side of the heart through a line placed in a large blood vessel in the neck or groin and is positioned into the pulmonary artery. Complications are uncommon and are mainly related to line insertion. Occasionally bleeding inside the lung and changes in heart rhythm have been reported, but death associated with a PAC is rare. The objective of this systematic review was to provide an up-to-date assessment of evidence on the effectiveness of PAC on death rates, days spent in ICU, days spent in hospital, and cost of care for adult ICU patients.

We identified 13 studies comparing patients treated with and without the use of a PAC that studied a total of 5686 patients. These were studies of patients undergoing routine major surgery (eight) and studies of patients who were critically ill and admitted to ICUs (five). We analysed the studies for any trial related risks and performed appropriate statistical analysis to minimize any risk of bias or errors. The quality of evidence is high from this review and further research is very unlikely to change our confidence in the estimate of effect except for cost analysis.

Our review found that there were no differences in the number of deaths during hospital stay, days spent in general ICUs, and days spent in hospital between patients who did and did not have a PAC inserted. Two US studies were analysed for hospital cost associated with or without a PAC and showed no difference in the cost. Neither group of patients studied showed any evidence of benefit or harm from using a PAC. The catheter is a monitoring tool that helps in diagnosis and is not a treatment modality. Insertion of PACs to help make treatment decisions in ICU patients should be individualized and should be done by experts in the field after adequate training in the interpretation of data. Studies need to be conducted to identify subgroups of ICU patients who can benefit, when the device is used in combination with standardized treatment plans, in reversing shock states and improving organ function. 


\begin{tabular}{|c|c|c|c|c|c|c|c|}
\hline \multirow{12}{*}{ 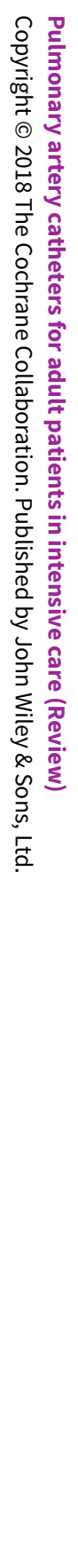 } & \multicolumn{7}{|c|}{$\begin{array}{l}\text { S U M M A R Y O F F I N D I N G S } \\
\text { Summary of findings for the main comparison. Pulmonary artery catheter for adult patients in intensive care }\end{array}$} \\
\hline & \multicolumn{7}{|c|}{ Pulmonary artery catheter for adult patients in intensive care } \\
\hline & \multicolumn{7}{|c|}{$\begin{array}{l}\text { Patient or population: Adult patients in intensive care } \\
\text { Settings: Intensive care unit } \\
\text { Intervention: Pulmonary artery catheter }\end{array}$} \\
\hline & \multirow[t]{3}{*}{ Outcomes } & \multicolumn{2}{|c|}{ Illustrative comparative risks* $(95 \% \mathrm{Cl})$} & \multirow{3}{*}{$\begin{array}{l}\text { Relative effect } \\
(95 \% \mathrm{CI})\end{array}$} & \multirow{3}{*}{$\begin{array}{l}\text { No of Partici- } \\
\text { pants } \\
\text { (studies) }\end{array}$} & \multirow{3}{*}{$\begin{array}{l}\text { Quality of the } \\
\text { evidence } \\
\text { (GRADE) }\end{array}$} & \multirow[t]{3}{*}{ Comments } \\
\hline & & Assumed risk & Corresponding risk & & & & \\
\hline & & Control & Pulmonary artery Catheter & & & & \\
\hline & $\begin{array}{l}\text { ICU length of stay (gen- } \\
\text { eral intensive care pa- } \\
\text { tients) } \\
\text { Follow-up: mean } 10-12 \\
\text { days }\end{array}$ & & $\begin{array}{l}\text { The mean ICU length of stay (general inten- } \\
\text { sive care patients) in the intervention groups } \\
\text { was } \\
\mathbf{0 . 5} \text { higher } \\
\text { (0.44 to } 0.55 \text { higher) }\end{array}$ & & $\begin{array}{l}2723 \\
\text { (4 studies) }\end{array}$ & $\begin{array}{l}\oplus \oplus \oplus \oplus \\
\text { high }\end{array}$ & \\
\hline & $\begin{array}{l}\text { Hospital length of stay } \\
\text { (general intensive care } \\
\text { patients) } \\
\text { Follow-up: mean } 14-22 \\
\text { days }\end{array}$ & & $\begin{array}{l}\text { The mean hospital length of stay (general } \\
\text { intensive care patients) in the intervention } \\
\text { groups was } \\
\text { 0.8 lower } \\
\text { ( } 2.71 \text { lower to } 1.12 \text { higher) }\end{array}$ & & $\begin{array}{l}1689 \\
\text { (2 studies) }\end{array}$ & $\begin{array}{l}\oplus \oplus \oplus \oplus \\
\text { high }\end{array}$ & \\
\hline & $\begin{array}{l}\text { Hospital length of stay } \\
\text { (high-risk surgical pa- } \\
\text { tients) } \\
\text { Follow-up: mean } 10-22 \\
\text { days }\end{array}$ & & $\begin{array}{l}\text { The mean hospital length of stay (high-risk } \\
\text { surgical patients) in the intervention groups } \\
\text { was } \\
\mathbf{0 . 3 5} \text { higher } \\
\text { ( } 0.05 \text { lower to } 0.75 \text { higher) }\end{array}$ & & $\begin{array}{l}503 \\
\text { (5 studies) }\end{array}$ & $\begin{array}{l}\oplus \oplus \oplus \oplus \\
\text { high }\end{array}$ & \\
\hline & $\begin{array}{l}\text { Cost of care (hospital } \\
\text { charges, 1000s of US dol- } \\
\text { lars) }\end{array}$ & & $\begin{array}{l}\text { The mean cost of care (hospital charges, } \\
1000 \text { 's of us dollars) in the intervention } \\
\text { groups was } \\
\text { 0.9 higher } \\
\text { ( } 2.62 \text { lower to } 4.42 \text { higher) }\end{array}$ & & $\begin{array}{l}191 \\
\text { (2 studies) }\end{array}$ & $\begin{array}{l}\oplus \oplus \ominus \ominus \\
\mathbf{l o w}^{1}\end{array}$ & \\
\hline & \multirow{2}{*}{$\begin{array}{l}\text { Combined mortality of } \\
\text { all studies } \\
\text { Follow-up: mean } 28-60 \\
\text { days }\end{array}$} & \multicolumn{2}{|c|}{ Study population } & \multirow[t]{2}{*}{$\begin{array}{l}\text { RR 1.01 } \\
(0.95-1.08)\end{array}$} & \multirow[t]{2}{*}{$\begin{array}{l}5686 \\
\text { (13 studies) }\end{array}$} & \multirow[t]{2}{*}{$\begin{array}{l}\oplus \oplus \oplus \oplus \\
\text { high }\end{array}$} & \\
\hline & & 297 per 1000 & $\begin{array}{l}\mathbf{3 0 1} \text { per } \mathbf{1 0 0 0} \\
\text { (273 to } 333 \text { ) }\end{array}$ & & & & \\
\hline
\end{tabular}


*The basis for the assumed risk (e.g. the median control group risk across studies) is provided in footnotes. The corresponding risk (and its $95 \% \mathrm{Cl}$ ) is based on the assumed risk in the comparison group and the relative effect of the intervention (and its $95 \% \mathrm{CI}$ ).

Cl: Confidence interval; RR: Risk ratio;

GRADE Working Group grades of evidence

High quality: Further research is very unlikely to change our confidence in the estimate of effect.

Moderate quality: Further research is likely to have an important impact on our confidence in the estimate of effect and may change the estimate.

Low quality: Further research is very likely to have an important impact on our confidence in the estimate of effect and is likely to change the estimate.

Very low quality: We are very uncertain about the estimate.

1 Only 2 studies reported the hospital cost out of 5, in 1990 to 91 . The applicability in present situation after 20 years is questionable. The cost cannot be compared across various countries. 


\section{B A C K G R O U N D}

\section{Description of the condition}

The concept of right heart catheterization was first introduced by $\mathrm{Dr}$ Warner Forrsmann in 1929 (Chatterjee 2009). It was in 1970 that Dr HJ Swan and Dr William Ganz introduced the flowdirected balloon-tipped catheter that led to a paradigm shift in the way right heart catheterizations are performed at the bedside using intracardiac pressure tracings, without utilizing fluoroscopic guidance. Since then, the pulmonary artery catheter (PAC), also called a Swan-Ganz catheter, has been utilized in the management of intensive care unit (ICU) patients for the past 42 years (Swan 1970). A PAC provides the intensivist with critical haemodynamic data that includes cardiac output, mixed venous oxygen saturation, intrapulmonary and intracardiac pressures. These variables together with additional derived variables calculated from these measurements, such as pulmonary and systemic vascular resistance, right and left ventricular stroke work indices, right and left ventricular end-systolic and enddiastolic indices, right ventricular ejection fraction, arterial and venous oxygen content, oxygen consumption, oxygen delivery and oxygen extraction ratio, are used to guide treatment of critically ill patients. On average, in the United States (US) one million PACS were used annually in the 1990s (Connors 1996).

\section{Description of the intervention}

A PAC is a diagnostic and haemodynamic monitoring tool. The PAC is used by clinicians in adult medical ICUs, cardiac catheterization laboratories and coronary care units (CCUs). It is used for pre-operative optimization of haemodynamics, intraoperative monitoring and postoperative management of critically ill patients, and in cardiothoracic surgery patients such as coronary artery bypass graft (CABG, or bypass surgery) and valvular surgeries to guide therapy and differentiate various types of shock states.

For the procedure, the balloon-tip catheter is floated through a central venous access, through the right atrium and right ventricle to the pulmonary artery and left in position to measure the filling pressures of the heart. When the balloon is inflated it measures pulmonary capillary wedge pressure or occlusion pressure, which is an indirect measure of left ventricular end-diastolic pressure. Newer PACs have the capability of measuring central venous oxygen saturation and continuous cardiac output.

Insertion of a PAC requires a central venous access and its complications are mainly related to the line placement. Advanced training and ultrasound guidance of line insertions have reduced some of these risks in recent years (Lamperti 2012). Longterm central line related complications such as infections are not attributable to PAC insertion. Additional risks of floating a PAC include possible pulmonary artery rupture and subsequent bleeding or pulmonary infarction (lung tissue loss). In an attempt to review the risk and benefits of a PAC the American Society of Anesthesiologist reviewed 860 publications. Though major morbidity related to PAC seems uncommon, minor atrial and ventricular arrhythmias (heart rhythm abnormalities) are common during catheter insertion (>20\%).

Complications from PAC can be classified as: (air in blood vessels) and pneumothorax (air outside the lungs), reported in less than 3.6\%;

2. those arising from catheterization (severe dysrhythmias, right bundle branch block and complete heart block), seen in $0.3 \%$ to $3.8 \%$; and

3. those due to prolonged catheter residence (pulmonary artery rupture, pulmonary infarction, venous thrombosis (clots in vein)), in from $0.03 \%$ to $3 \%$.

The task force states that overall deaths attributed to a PAC are $0.02 \%$ to $1.5 \%$ (ASA task force on PAC 2003).

\section{How the intervention might work}

Pulmonary artery catheters (PACS) were initially widely used by cardiologists in the management of patients with acute heart failure or cardiac tamponade, major surgery patients with a cardiac history, and cardiogenic shock. The first data on PACs were published in 1987, in an observational study from 16 different hospitals that looked at time trends in incidence rates, on inhospital and long-term case fatality rates in patients with acute myocardial infarction (Gore 1987). The study had 3000 patients and showed a sharp rise in the use of PACs from 1975 to $1984(7.2 \%$ to $19.9 \%$ ) with no difference in mortality in the group of patients with cardiogenic shock. There was, however, increased mortality and hospital length-of-stay (LOS) in patients with congestive heart failure and hypotension who received a PAC. Interestingly, the study showed better long-term survival in patients with cardiogenic shock who received a PAC at six months and five years. In 1990, another non-experimental study showed increased mortality in patients who received a PAC (Zion 1990). In this study only 67 patients had a PAC and the authors concluded that it was unlikely that the PAC itself had led to the increased mortality. This led to the first randomized controlled trial (RCT) of PACs in 1991 (Guyatt 1991). The European Society of Intensive Care Medicine later came out with a consensus document recommending the indications for use of PACS (ESICM 1991).

In 1996, results of a prospective, non-experimental cohort study that involved 5700 patients with nine different illnesses, of which 2100 received PACs, showed increased mortality with PAC use (Connors 1996). The publication sparked a lot of controversy primarily because it was a non-randomized comparison (Assoc. Press 1996). A Consensus Statement issued by the Society of Critical Care Medicine identified that the published evidence to support the use of PAC was paltry and scientifically very poor, and the need for clinical trials was highlighted (PAC Consensus 1997). Recent evidence suggests that use of a PAC and therapy based on the information obtained reduces surgical morbidity and mortality (Brienza 2009; Gurgel 2011; Hamilton 2011). Until now, controversy exists with the use of PACs in various clinical settings in ICUs. If clinicians acquire adequate knowledge and expertise, PAC data and monitoring may be valuable to guide therapy in critically ill patients. The device has to produce data that are reliably interpreted by attending staff. These data are usually not available from other sources and can lead to a change in therapy that is linked to improved outcomes. The therapies that might be altered or added include pressors, inotropes, vasodilators, fluids, diuretics and lusitropic agents.

1. those from central venous access (arterial puncture, postoperative neuropathy (pain and sensation deficit), air embolism 


\section{Why it is important to do this review}

This is an update of a Cochrane review first published in 2006 (Harvey 2006) about PAC use in adult ICU. The initial review identified 12 studies and the main findings were that PAC did not affect the mortality of patients, hospital or ICU LOS, and the cost based on charges billed to the patients were on average higher in the PAC groups.

Since the adoption of the PAC into clinical practice, several observational studies and five RCTs involving general ICU patients (Binanay 2005; Harvey 2005; NHLBI 2006; Rhodes 2002; Richard 2003) have been conducted to determine its effect on patient mortality. These studies did not show a benefit of the use of a PAC in patient outcomes. There was significant negative publicity, especially in the US, leading to a decline in the use of PACs in clinical practice. A report looking at trends in the use of PACs in the US, published in 2007 (Wiener 2007), reported a 65\% reduction in its use among medical ICUs and $63 \%$ reduction in its use among surgical ICUs from 1993 to 2004. Recently, however, there has been criticism in the way the data from these studies were interpreted (Greenberg 2009). Authors have argued that the PAC is a monitoring device and that mortality must not be a basis for determining the efficacy of monitors. Patient outcomes are not dependent upon insertion of a PAC; outcomes are dependent upon appropriate interpretation of acquired data followed by administration of appropriate care. It has also been argued that studies were not adequately powered to provide conclusions on rare outcomes like patient mortality (Greenberg 2009). Also, it would have been challenging to adequately blind physicians to the PAC, as it is hard to conceal the presence of a PAC in a patient.

The timeliness of institution of care with regard to PAC insertion has also been questioned. In a meta-analysis performed in 1996 (Cooper 1996) that showed no benefit of goal-directed therapy using a PAC in a general ICU population, only one study was considered of high quality (Gattinoni 1995). The study randomized 762 patients in one of three categories, cardiac index $(\mathrm{Cl}) 2.5$ to $3.5 \mathrm{ml} / \mathrm{min} / \mathrm{m}^{2} ; \mathrm{Cl}>4.5 \mathrm{ml} / \mathrm{min} / \mathrm{m}^{2}$; and central venous oxygen saturation $>70 \%$. The patients in the study, however, did not receive the PAC until up to 72 hours after development of shock. The patients in the most recent Fluid and Catheter Treatment Trial (FACTT) (NHLBI 2006) that studied the safety and efficacy of PACguided versus central venous pressure (CVP)-guided treatment of patients with acute lung injury also did not receive therapy until a mean of 25 hours after establishment of diagnosis.

In the light of the aforementioned studies and meta-analysis, and the ongoing debate on appropriate use of the PAC, the purpose of the current systematic review was to search for all the available evidence from RCTs and to define the best evidence base for current clinical practice.

\section{OB JECTIVES}

To systematically search for and synthesize all the evidence from randomized controlled trials (RCTs) that utilized pulmonary artery catheters (PACs) in the management of critically ill patients in the intensive care units (ICUs) and analyse the effect of the PAC on mortality, length of stay and cost of care.

\section{METHODS}

\section{Criteria for considering studies for this review}

\section{Types of studies}

We included RCTs with or without blinding. We placed no limitation on the language of publication.

\section{Types of participants}

We included studies with more than $50 \%$ adult patients (16 years of age and above) where a PAC was placed in an ICU setting (see definition below) or placed during a surgical procedure leading to ICU admission.

We defined an ICU as including: an intensive care unit (ICU); a paediatric intensive care unit; a high dependency unit (HDU); a postanaesthesia care unit (PACU); or a service-specific critical care unit (CCU).

We excluded studies that included patients in whom death had been declared using brain stem death criteria and who had a PAC placed solely for organ support prior to organ donation.

We excluded studies comparing PAC with the new less invasive techniques used to measure the haemodynamic parameters, such as continuous pulse contour cardiac analysis (PiCCO).

\section{Types of interventions}

We included RCTs in which patients treated in an ICU were randomized to be managed with a PAC (of any type) in one arm of the trial and without a PAC in another arm.

\section{Types of outcome measures}

\section{Primary outcomes}

1. All types of hospital mortality ( 28 days, 30 days, 60 days or ICU mortality)

\section{Secondary outcomes}

1. Length of stay (LOS) in ICU

2. LOS in hospital

3. Costs of hospital care

\section{Search methods for identification of studies}

\section{Electronic searches}

We searched the Cochrane Central Register of Controlled Trials (CENTRAL) (The Cochrane Library 2011, Issue 12), see Appendix 1 for the search strategy; MEDLINE (OvidSP) (1954 to January 2012), see Appendix 2; EMBASE (OvidSP) (1980 to January 2012), see Appendix 3; CINAHL (EBSCOhost) (1982 to January 2012), see Appendix 4.

\section{Searching other resources}

\section{Grey literature search}

We searched the grey literature including NYAM Grey Literature Collection, OAlster - Digital Resource from Open Archive Collections, Directory of Open Access Journals and OpenDOAR; clinical trial registers (International Standard Randomised Controlled Trial Number Register, Eur Clinical Trials Register (new 2011) and WHO International Clinical Trial Registry Platform); 
dissertations and theses; open access journals; meeting abstracts and conference abstracts (handsearched for original review). See Appendix 5 to see a list of all resources and terms.

\section{Previous reviews}

We reviewed the studies cited in the previously published review (Harvey 2006), now updated in 2012.

\section{Manual searches}

We handsearched conference abstracts from the four major European and North American annual critical care conferences, run by the European Society of Intensive Care Medicine, the Society of Critical Care Medicine (US), the American Thoracic Society, and the Erasme Hospital, Free University of Brussels (from 1995 to 2001). For the update we added the above grey literature search in 2012 (see Appendix 5).

\section{Citation review}

We checked the references lists of included citations and potentially relevant citations, identified from the electronic searches, for further relevant studies. We also checked the reference lists of any systematic or narrative reviews identified from the searches.

\section{Experts}

We contacted key people in the field of critical care, including clinicians and other researchers, to identify relevant studies.

\section{Industry}

We contacted relevant pharmaceutical and equipment companies for published and unpublished reports to identify relevant studies.

\section{Data collection and analysis}

\section{Selection of studies}

In the update we included all the originally selected studies (Harvey 2006) and added new studies searched for from April 2005 to January 2012. Four authors screened the updated search results independently (SR, ND, MG and AK). One author (SC) searched the grey literature. We obtained the full text articles of the studies that seemed to be relevant during our screening. We resolved discrepancies through discussion.

\section{Data extraction and management}

Two authors independently reviewed the full text reports of each included study (update in 2012 by SR or MG, AK; and original review (Harvey 2006) in 2006 by SH, DY or WB, KR) and extracted the following data:

- general information, including title, lead author, journal, publication details and name of reviewer;

- study characteristics, including verification of study eligibility, characteristics of study population, risk of bias of included studies and interventions;

- outcome measures and results, including length of follow-up, drop-outs and measures of effect.

We resolved differences in the data extracted between the two authors by discussion. We documented the reasons for excluding studies. Two authors (SH and DY) double-entered data into Review Manager in the original version (Harvey 2006). In the 2012 update two authors (SR and MG) independently extracted the data and created risk of bias tables. We resolved the discrepancies through discussion. Two authors (SR and ND) entered data into Review Manager (RevMan 5.1).

\section{Assessment of risk of bias in included studies}

We used the Cochrane Handbook for Systematic Reviews of Interventions (the Handbook) (Higgins 2011) to assess the risk of bias for each study. Two authors (SR and MG) independently assessed the risk of bias for each study considering the following seven domains for bias: random sequence generation (selection bias), allocation concealment (selection bias), blinding of participants and personnel (performance bias), blinding of outcome assessment (detection bias), incomplete outcome data (attrition bias), selective reporting (reporting bias) and other bias. For each bias we expressed our judgement as: at high risk (plausible bias that seriously weakens confidence in the results), low risk (unlikely to seriously alter the results) and unclear risk (raises some doubt about the results) of bias. We also gave the reason for our judgement. Three authors (SR, MG and AK) resolved disagreements by reviewing the data together.

We agreed that complete blinding of the treating physicians may not be feasible at the bedside, but the investigator could be blinded. If the investigator was blinded or did not participate in patient care, we agreed that those studies were at low risk for performance bias. If it was a single centre study and investigators and the treating physicians were the same person, we agreed that performance bias was at high risk. We agreed that blinding of outcome assessment was feasible in studies such as in a multicentre trial if the outcome assessor did not participate in patient care.

\section{Measures of treatment effect}

For dichotomous data (mortality), we used risk ratio (RR) as the summary measure. For continuous data (LOS, cost of care) we used mean difference as the summary measure.

\section{Unit of analysis issues}

We also combined studies that had included other interventions in addition to the PAC in a separate subgroup analysis. For studies that had two PAC intervention groups, we combined the two groups.

\section{Dealing with missing data}

We did not contact any original investigators to request information about missing data. Our search was comprehensive and missing studies was unlikely. One study (Bender 1997) did not report all the details of the outcome measures postoperatively for the control group and we judged the study as at high risk of selective reporting bias in the analysis.

\section{Assessment of heterogeneity}

We used $\mathrm{Chi}^{2}$ test $\left(\mathrm{X}^{2}\right)$ to assess whether observed differences in results were compatible with chance alone. A large $\mathrm{Chi}^{2}$ statistic relative to its degree of freedom provides evidence of heterogeneity of intervention effects (variation in effect estimates beyond chance). For quantifying inconsistency we used the 12 statistic to describe the percentage of the variability in effect estimates that was due to heterogeneity rather than sampling error (chance). An $\mathrm{L}^{2}$ of $0 \%$ to $40 \%$ might not be important, $30 \%$ to $60 \%$ was moderate heterogeneity, $50 \%$ to $90 \%$ was substantial 
heterogeneity and $75 \%$ to $100 \%$ was interpreted as considerable heterogeneity (Higgins 2011). When the heterogeneity was low in the outcome measures meta-analysis was considered appropriate.

Clinical heterogeneity was explored by conducting subgroup analysis. To incorporate heterogeneity among studies randomeffects model meta-analysis was used. We did not exclude any studies based on conflicting results, which minimized heterogeneity. We performed sensitivity analysis with and without any potential outlying studies. We did not perform meta-regression to investigate heterogeneity in a subgroup analysis due to low sample size of the subgroups.

\section{Assessment of reporting biases}

We tried to minimize the impact of publication bias through a thorough review of all the published data and grey literature. We dealt with location bias by searching MEDLINE, EMBASE, CENTRAL, CINAHL and grey literature using a variety of search terms. We assessed publication bias using a funnel plot for the combined mortality outcome.

\section{Data synthesis}

We summarized the aims, methods and outcome measures of interest (mortality, LOS in ICU and hospital, and costs of care). We expressed mortality as absolute numbers and percentages, and we expressed LOS as mean, median, and range for survivors and non-survivors reported separately. The primary outcome measure of interest was in-hospital mortality at any time; if this was not reported, we used the mortality at the point closest to hospital discharge. We expressed results on costs of care in a range of measures. The secondary outcome measures were ICU and hospital LOS and cost of care.

We calculated risk ratio (RR) for mortality across studies and mean days for LOS using a random-effects model in RevMan 5.1 (Higgins 2011; RevMan 5.1). All analyses were based on the intention-to-treat principle. Among the five studies that reported various costs, only two studies reported the hospital cost and a fixed-effect model was used to analyse the cost.

One study (Pearson 1989) allowed patients to cross-over to the PAC group after randomization due to ethical reasons. We combined the number of patients in the PAC group for mortality analysis and reported the hospital LOS separately. Another study (Guyatt 1991) allowed sicker patients to cross-over to the PAC group. We did not perform paired-analysis due to the low number of recruitments. The weights of these two studies were low in the meta-analysis.

\section{Subgroup analysis and investigation of heterogeneity}

Patients admitted to ICU are a heterogeneous group in terms of diagnosis, prognosis and resource utilization. This heterogeneity exists both among patients within a single ICU and among the case mix of patients admitted to medical and surgical ICUs. Therefore, we performed subgroup analysis combining data from studies that had included patient populations with similar characteristics. We did subgroup analysis of mortality separately in general intensive care patients, high-risk surgical patients, and studies of perioperative monitoring to investigate the effect of the heterogeneity of the studies. We analysed ICU LOS and hospital LOS separately for surgical and medical patients.

\section{Sensitivity analysis}

We performed sensitivity analysis to examine the impact of studies which had a high risk of bias. This was achieved by removing a study from the meta-analysis and analysing the effect of removing that study on overall mortality. We performed a similar sensitivity analysis with hospital LOS and ICU LOS with studies that had a high risk of bias.

\section{RE S U L T S}

\section{Description of studies}

\section{Results of the search}

We identified a total of 4521 citations (3800 in 2006 (Harvey 2006) and 721 in 2012) (Figure 1). After screening by title and then abstract, we obtained full paper copies for 46 (41 in 2006 and five in 2012) citations that were potentially eligible for inclusion in the review. Of these, 28 did not fulfil our inclusion criteria and were excluded for the reasons described in the table Characteristics of excluded studies. 
Figure 1. PAC for adult patients intensive care study flow diagram. 0 - Original review in 2006. U - Updated review in 2012.

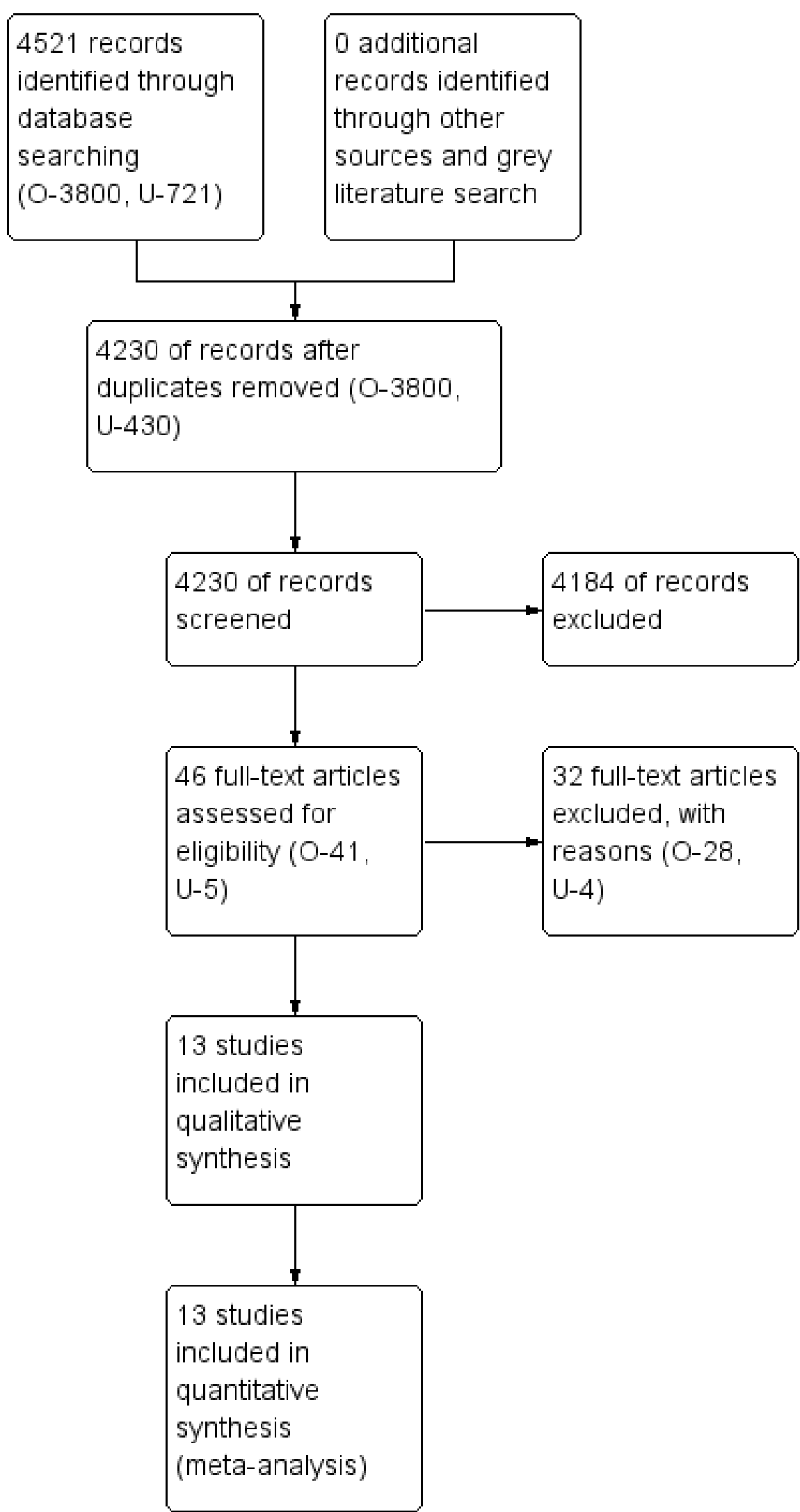




\section{Included studies}

We included 13 RCTs. These 13 studies enrolled a total of 5686 patients. All patients were admitted to ICU and randomized to either a PAC group or control group with or without a central venous catheter (CVC) to monitor haemodynamics. All RCTs reported hospital mortality as the primary outcome (Analysis 1.1) and some reported ICU LOS and hospital LOS as secondary outcomes (Characteristics of included studies). The studies fell broadly into two groups, as follows.

1. General ICU studies: we included five studies of general intensive care patients with varying diagnoses (acute lung injury (NHLBI 2006); acute ventilatory failure (Guyatt 1991); shock (Rhodes 2002; Richard 2003)); and one study of patients admitted to the ICU requiring PAC insertion as deemed appropriate by the attending physician (Harvey 2005).

2. High-risk surgery studies: we included eight studies of patients undergoing high-risk surgery. These studies were divided into two subgroups.

a) Studies investigating the effectiveness of preoperative optimization of haemodynamics. We identified five studies in this category, for vascular surgery (Bender 1997; Berlauk 1991); abdominal, thoracic, vascular or orthopaedic surgery (Sandham 2003); abdominal reconstructive surgery (Valentine 1998); and predefined high-risk surgical patients (Shoemaker 1988). b) Studies comparing the effectiveness of managing patients during the perioperative period where patients were admitted to the ICU following surgery. We identified three studies in this category, in aortic reconstruction (Isaacson 1990; Joyce 1990) and elective cardiac surgery patients (Pearson 1989).

\section{Excluded studies}

We excluded non-RCTs and systematic reviews. We also excluded RCTs that compared PACs with non-invasive haemodynamic monitoring methods and studies that had their primary outcome of interest as fluid management (see Characteristics of excluded studies).

\section{Risk of bias in included studies}

We analysed seven domains of potential risk of bias for the included studies (Figure 2). We rated blinding of participants and personnel and blinding of outcome assessment at high risk in half of the included studies and at low risk in one third of the studies. Regardless of the high risk of performance bias, these studies were included because of the low weight of the studies in the meta-analysis. We rated three quarters of the studies at low risk of selection bias, attrition bias and reporting bias (Figure 3). We performed a sensitivity analysis by removing all the trials that had high and unclear risk of bias and the results remained the same. Publication bias appeared to be unlikely as the funnel plot is symmetric, which also confirms the absence of effect of study size on the outcome (Figure 4).

Figure 2. Risk of bias graph: review authors' judgements about each risk of bias item presented as percentages across all included studies.

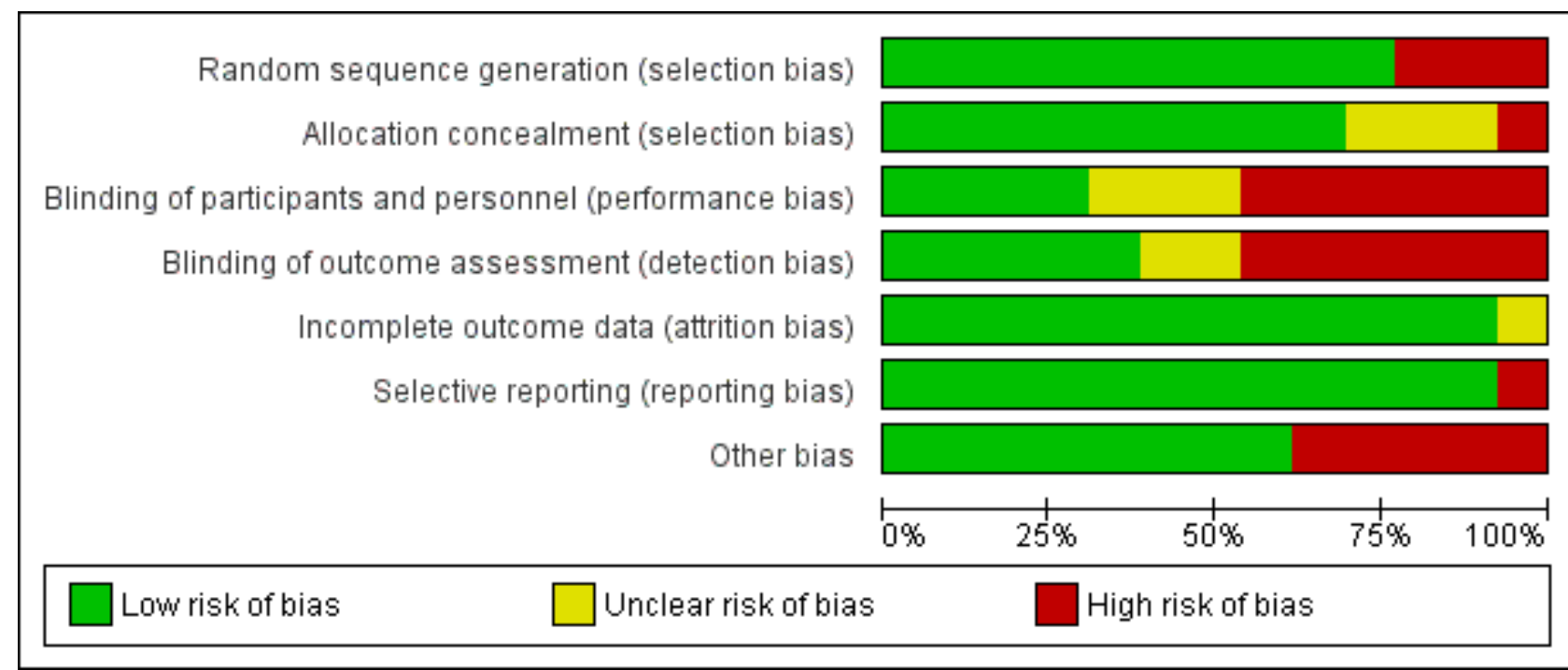


Figure 3. Risk of bias summary: review authors' judgements about each risk of bias item for each included study.

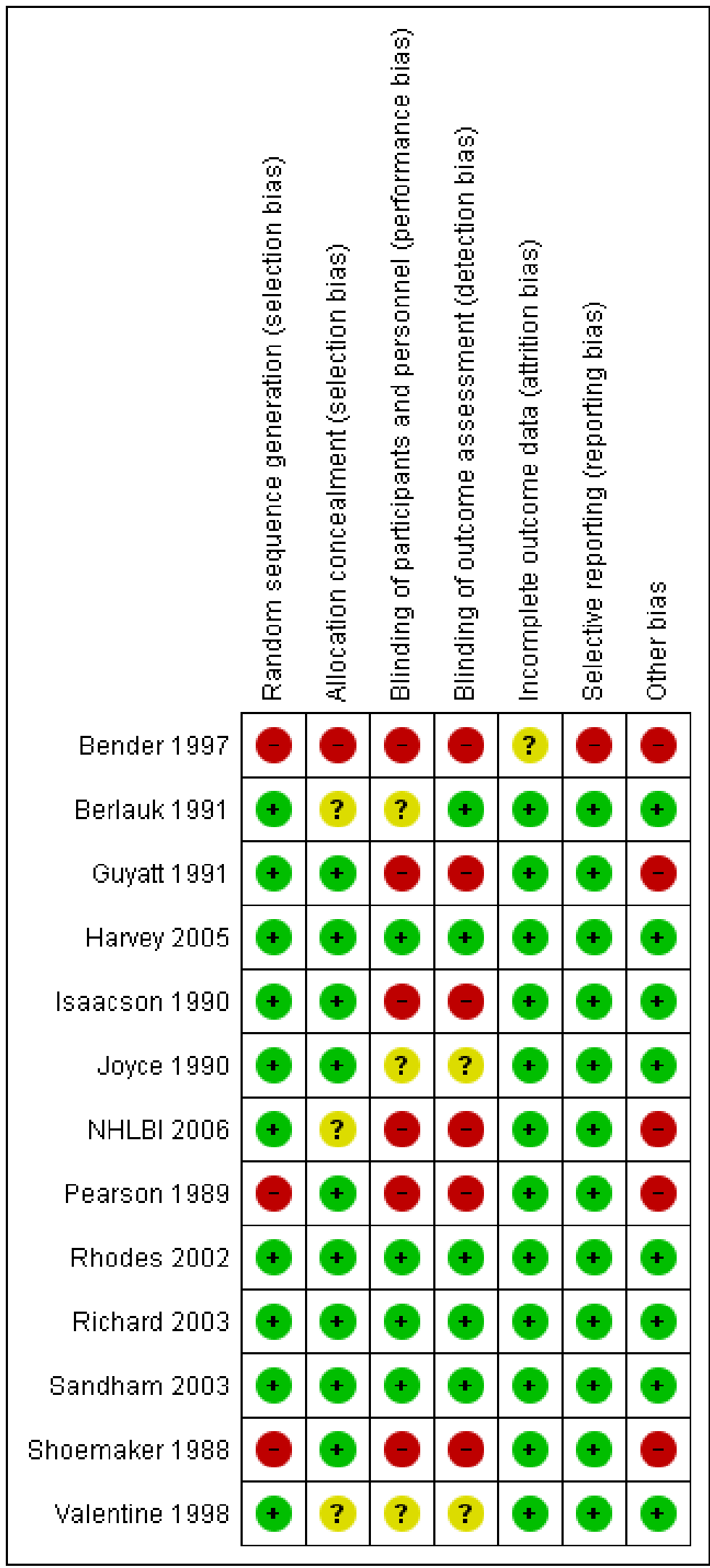


Figure 4. Funnel plot of comparison: 5 PAC versus no PAC outcome: 5.1 Combined mortality of all studies.

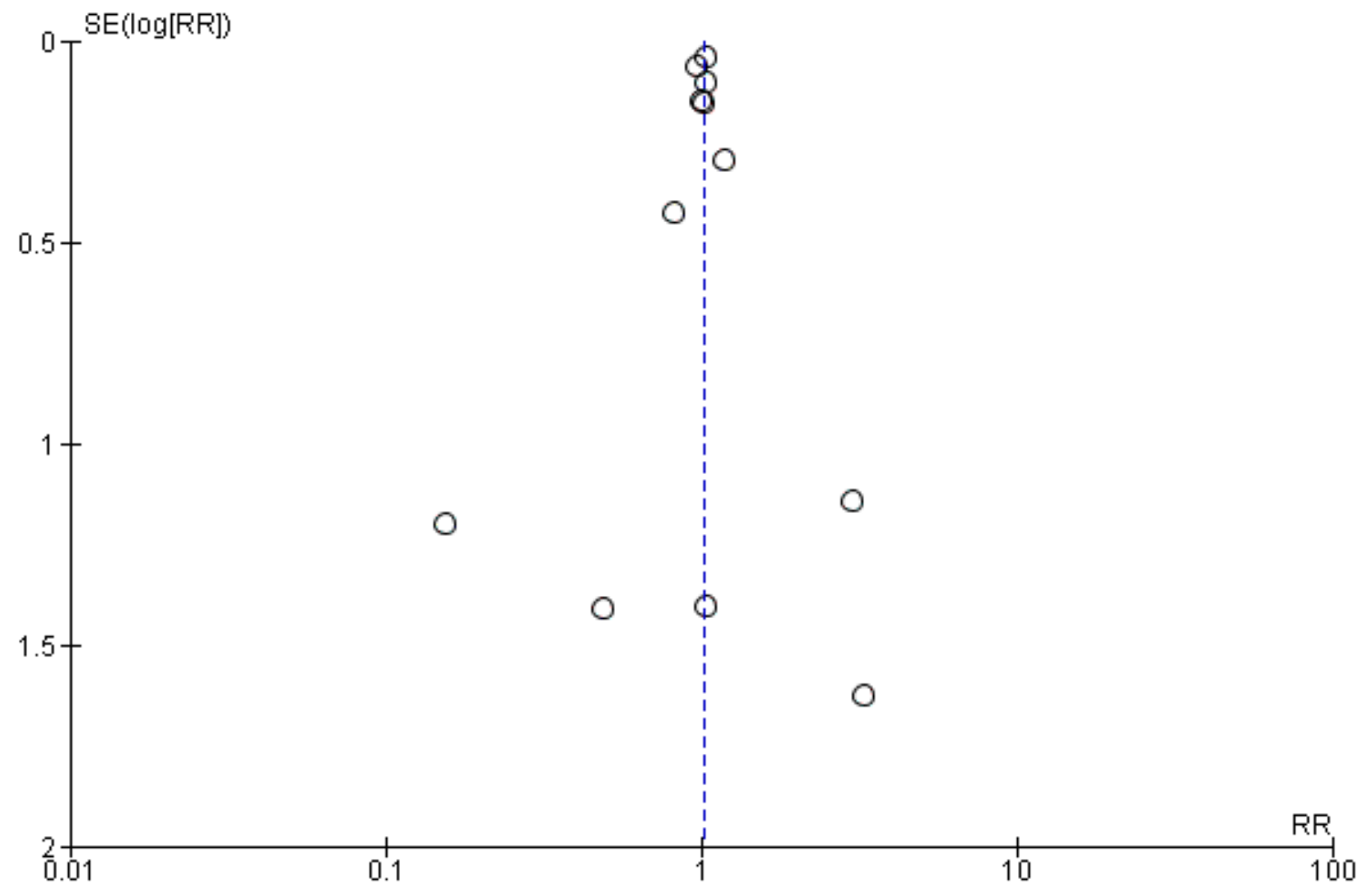

\section{Allocation}

Nine studies clearly used adequate randomization and concealment schemes and were classified as low risk for bias (Guyatt 1991; Harvey 2005; Isaacson 1990; Joyce 1990, Pearson 1989; Rhodes 2002; Richard 2003; Sandham 2003; Shoemaker 1988). Three studies had an unclear risk due to not reporting allocation details (NHLBI 2006; Valentine 1998) and inconsistent methods of allocation (Berlauk 1991). One high-risk study did not follow any acceptable methods (Bender 1997).

\section{Blinding}

\section{Performance bias}

The intervention under study, management with a PAC (with or without preoperative optimization), meant that it was not feasible to completely blind the study participants and some study personnel to the assigned treatment group. However, if treating physicians and patient care decision makers were not the investigators, performance bias could be minimized.

Four studies were at low risk for blinding of participants or performance bias due to the multicentre nature of the study or investigators were not the providers (Harvey 2005; Rhodes 2002; Richard 2003; Sandham 2003). Five studies were at high risk for performance bias. One study, even though a multicentre trial, was protocol driven and allowed the PAC patients to change over to a CVC at the discretion of the treating physician (NHLBI 2006). In two studies the providers were the investigators (Isaacson 1990; Shoemaker 1988) and in two other studies the providers were allowed to change the group or cross-over to PAC after randomization (Guyatt 1991; Pearson 1989).

Three studies gave insufficient information to assess performance bias (Berlauk 1991; Joyce 1990; Valentine 1998) (Figure 3).

\section{Detection bias}

The nature of the intervention under study meant that complete blinding of outcome was not feasible, however detection bias could be minimized if the investigator and treating physician were different personnel. Performance bias and detection bias shared similar high and unclear risks in all the studies except in one study. Berlauk et al (Berlauk 1991) had low risk because investigators (anaesthesiologists) were involved for a short period of the first 18 hours only and were unlikely to have influenced the mortality or hospital LOS thereafter. Two studies gave insufficient information and the risk was unclear (Joyce 1990; Valentine 1998). Four studies were at low risk (Harvey 2005; Rhodes 2002; Richard 2003; Sandham 2003). Four other studies were at high risk (Guyatt 1991; Isaacson 1990; Pearson 1989; Shoemaker 1988) however, given their low weights in the meta-analyses, the impact on the effect estimate of removing them would have been negligible. The FACTT study (NHLBI 2006) was at high risk for detection bias because only weaning of vasopressors were under protocol management and not fluid management, which may have influenced the mortality and LOS outcomes. 


\section{Incomplete outcome data}

For all studies the number of patients withdrawn following randomization was low ( 0 to 3 ) and they were at low risk for attrition bias except one study, which did not report on one group of patients and the risk was unclear (Bender 1997). Another study had a higher number of withdrawals (13 in PAC group and 14 in CVC group) (Harvey 2005).

\section{Selective reporting}

All the studies were free of selective reporting bias except one (Bender 1997). We judged this study as high risk for reporting bias due to it not reporting any postoperative PAC group data. The study was of preoperative PAC monitoring, but one group of patients had a PAC postoperatively and this data may have impacted on the outcome.

\section{Other potential sources of bias}

Five studies had high risk for unknown bias. There was a high rate of cross-over from the control to the PAC group for two studies. In one study eight out of 17 patients allocated to the control group (47\%) were subsequently managed with a PAC (Guyatt 1991). Allowing sicker patients to cross-over to the PAC group after randomization may have contributed to the high mortality in the PAC group. The other study had both high-risk and lowrisk surgical patients, and 17 (57\%) crossed-over to a PAC during the postoperative period when the physicians felt that the patient needed invasive monitoring (Shoemaker 1988). One study had three groups initially and the additional groups four and five were included after randomization (Pearson 1989). Bender et al (Bender 1997) reported that one surgical intensivist cared for 104 patients and did not report the number of patients accounting for the LOS of 27 days. The FACCT (NHLBI 2006) study randomized the patients to a PAC or CVC group and at the same time applied another strategy of randomization to the same patients to a conservative or liberal fluid therapy group.

\section{Effects of interventions}

See: Summary of findings for the main comparison Pulmonary artery catheter for adult patients in intensive care

\section{Mortality}

Overall, four studies (Harvey 2005; Isaacson 1990; Sandham 2003; Shoemaker 1988) reported any hospital mortality. The remaining studies reported 28-day mortality (Rhodes 2002; Richard 2003); 30-day mortality (Bender 1997; Joyce 1990); 60-day mortality (NHLBI 2006); or ICU mortality (Pearson 1989). Three studies did not specify the type of mortality statistics (Berlauk 1991; Guyatt 1991; Shoemaker 1988). The combined mortality outcome for all studies, with 5686 patients, was not significantly different $(\mathrm{P}=$ 0.73 ) between the PAC and CVC groups (RR 1.01, 95\% Cl 0.95 to 1.08) (heterogeneity $\mathrm{Tau}^{2}=0.00 ; \mathrm{Chi}^{2}=5.26, \mathrm{df}=11(\mathrm{P}=0.92)$; $1^{2}=0 \%$ ) (Analysis 1.1; Figure 5; Figure 6). The overall outcome did not change with sensitivity analysis, by eliminating any single study. Large studies had almost similar weights and smaller studies had similar low weights, and no single study altered the weight of the analysis. To address the issue of analysing the mortality at different time points, various sensitivity analyses were conducted by removing groups of studies. Sensitivity analysis done by keeping the four studies with 1021 patients that reported only 28-day and 30-day mortality (Bender 1997; Joyce 1990; Rhodes 2002; Richard 2003) showed no difference in mortality (RR $0.98,95 \% \mathrm{Cl} 0.87$ to 1.10). By removing the combined 28 and 30-day mortality studies, the remaining nine studies with a total of 4665 patients also did not show any change in mortality (RR $1.03,95 \% \mathrm{Cl} 0.95$ to 1.11). Combining eight studies with 3665 patients that reported hospital or ICU mortality at any time point (sensitivity analysis done by removing the NHLBI study that reported 60-day mortality in combination with the four studies that reported 28 and 30-day mortality) also did not change any mortality (RR 1.03, 95\% Cl 0.95 to 1.11$)$.

Figure 5. Forest plot of comparison: 5 PAC versus no PAC (combined medical and surgical patients), outcome: 5.1 Combined mortality of all studies.

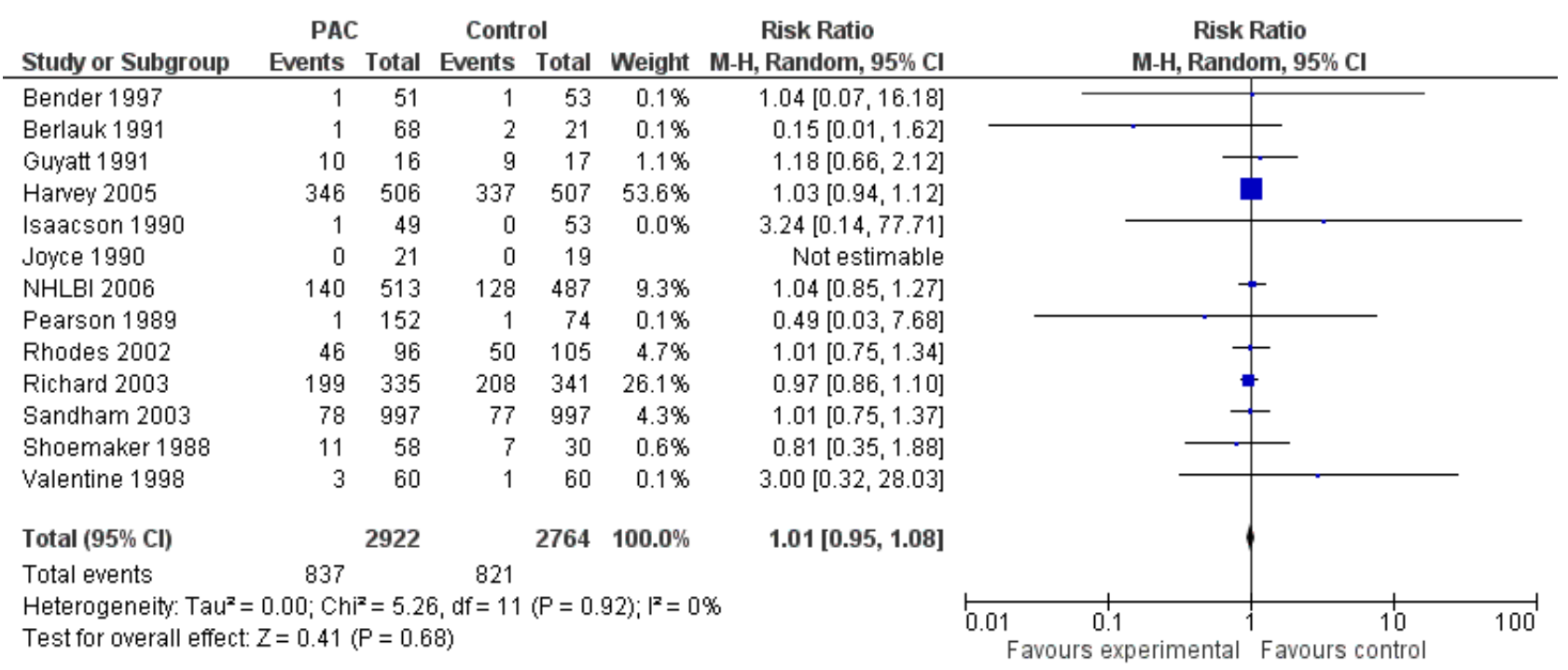


Figure 6. Forest plot of comparison: 1 PAC versus no PAC, outcome: 1.2 All types mortality (high-risk surgical patients).

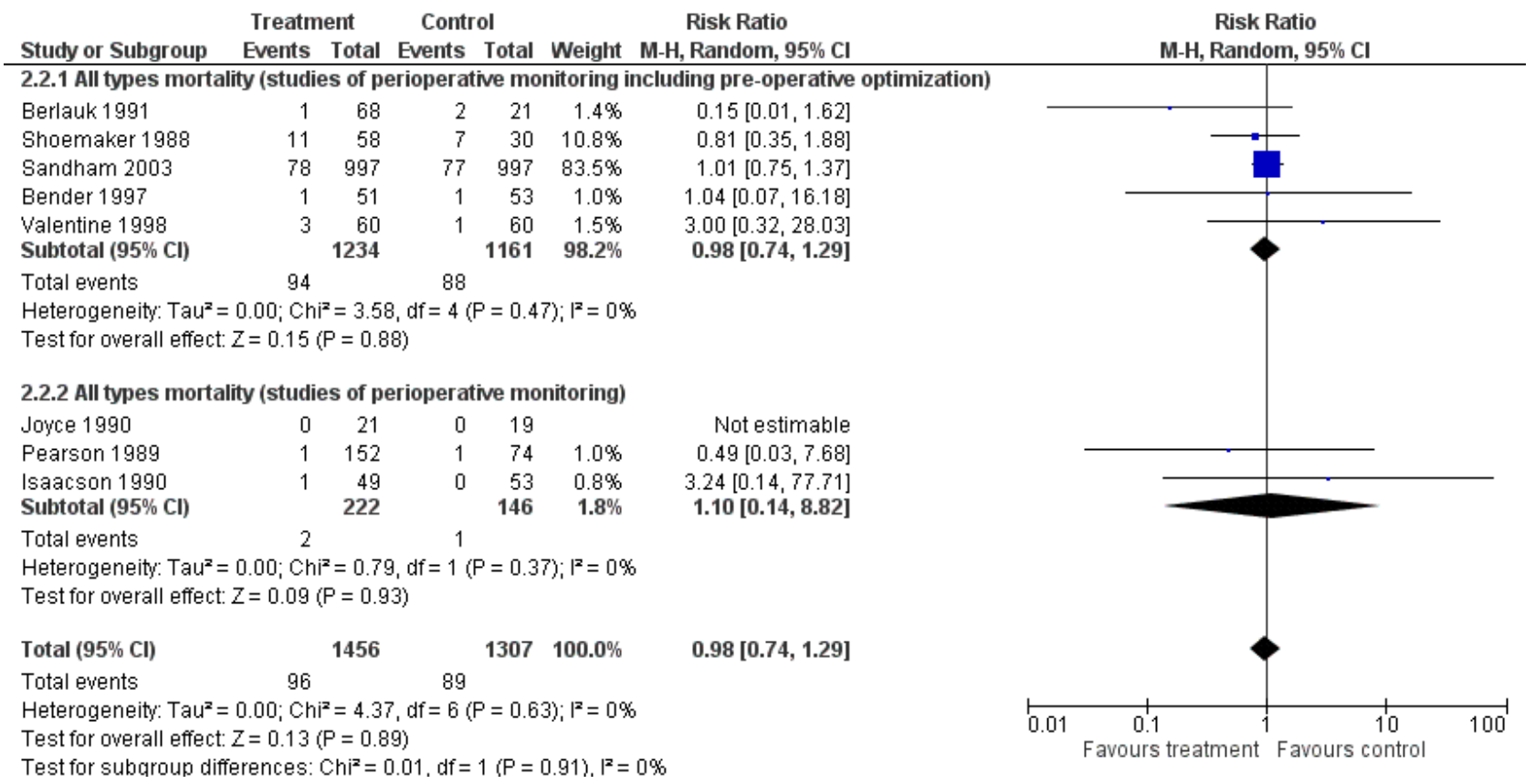

\section{Mortality: general ICU studies}

Data on 2923 patients enrolled into the five studies (Guyatt 1991; Harvey 2005; NHLBI 2006; Rhodes 2002; Richard 2003) were pooled to give a RR of 1.02 (95\% $\mathrm{Cl} 0.96$ to 1.09 ) comparing management with a PAC to management without a PAC (test for heterogeneity: $\left.\mathrm{Tau}^{2}=0.00 ; \mathrm{Chi}^{2}=1.04, \mathrm{df}=4(\mathrm{P}=0.90) ; \mathrm{I}^{2}=0 \%\right)$ (Analysis 2.1).

\section{Mortality: high-risk surgery studies}

Studies comparing mortality: preoperative optimization (using a PAC) with standard preoperative care

The numbers of deaths in each group for the five studies (Bender 1997; Berlauk 1991; Sandham 2003; Shoemaker 1988; Valentine 1998) are detailed in 'All types of mortality (high-risk surgical patients)' (Figure 6). We pooled data on the 2395 patients (total number, combined PAC and control groups) enrolled into these studies, which yielded a RR of 0.98 ( $95 \% \mathrm{Cl} 0.74$ to 1.29 ) comparing preoperative optimization with standard preoperative care (test for heterogeneity: $\left.\mathrm{Tau}^{2}=0.00 ; \mathrm{Chi}^{2}=3.58, \mathrm{df}=4(\mathrm{P}=0.47) ; \mathrm{I}^{2}=0 \%\right)$ (Analysis 2.2). Two studies (Berlauk 1991; Shoemaker 1988) had two PAC groups, which were combined for the pooled analysis.

\section{Studies comparing mortality: PACs with CVCs for monitoring patients} perioperatively

The number of deaths in each group for the three studies (Isaacson 1990; Joyce 1990; Pearson 1989) are detailed in 'All types of mortality (high-risk surgical patients)' (Figure 6). We pooled data on the 368 patients enrolled into these studies to give a RR of 1.10 (95\% $\mathrm{Cl} 0.14$ to 8.82 ) comparing management with and without a PAC based on intention to treat (test for heterogeneity: $\mathrm{Tau}^{2}=0.00 ; \mathrm{Chi}^{2}$ $\left.=0.79, \mathrm{df}=1(\mathrm{P}=0.37) ; \mathrm{I}^{2}=0 \%\right)$ (Analysis 2.2). One study (Pearson 1989) had two PAC groups, which were combined for the pooled analysis. Although a large proportion of patients in this study were reallocated from the control group to one of the two PAC groups, we analysed them as they were originally allocated, that is in the control group.

Combining data from all the high-risk surgery studies gave a pooled risk ratio of $0.98(95 \% \mathrm{Cl} 0.74$ to 1.29$)$ (heterogeneity $\mathrm{Tau}^{2}=0.00$; $\left.\mathrm{Chi}^{2}=4.37, \mathrm{df}=6(\mathrm{P}=0.63) ; \mathrm{I}^{2}=0 \%\right)$ (Analysis 2.2) (Figure 6).

\section{ICU length of stay}

Most studies reported the LOS in ICU for survivors and nonsurvivors combined (Appendix 6). Two studies (Joyce 1990; Sandham 2003) did not report the LOS in ICU.

\section{ICU LOS: general ICU studies}

General intensive care unit studies found no significant differences between the treatment and control groups in ICU LOC. Four studies with 2723 patients (Guyatt 1991; Harvey 2005; NHLBI 2006; Richard 2003) reported the mean (standard deviation) LOS in ICU and data were pooled to give a mean difference in days spent in ICU of $0.50(95 \% \mathrm{Cl} 0.44$ to 0.55$)$ comparing management with a PAC to management without a PAC (test for heterogeneity: $\mathrm{Tau}^{2}=0.00 ; \mathrm{Chi}^{2}$ $\left.=0.66, \mathrm{df}=2(\mathrm{P}=0.72) ; \mathrm{I}^{2}=0 \%\right)$ (Analysis 3.1$)$.

\section{ICU LOS: high-risk surgery studies}

In high-risk surgery studies, four (Bender 1997; Berlauk 1991; Shoemaker 1988; Valentine 1998) of the five studies of preoperative optimization and one (Isaacson 1990) of the three studies of perioperative monitoring only reported the mean LOS in ICU. When data were pooled to analyse the mean difference (MD) in days spent in ICU (MD 1.57 days, 95\% $\mathrm{Cl} 0.36$ to 2.79) comparing management with PAC to without a PAC, the test of heterogeneity was extraordinarily high (heterogeneity $\mathrm{Tau}^{2}=1.77 ; \mathrm{Chi}^{2}=136.51$, $\left.d f=4(P=0.00001) ; I^{2}=97 \%\right)$. Such high heterogeneity suggested that the combined high-risk surgery studies were very dissimilar 
and therefore not appropriate for meta-analysis to compare the ICU LOS outcome in this subgroup.

\section{Hospital length of stay}

Overall, nine studies reported the LOS in hospital. Again, most studies reported the LOS in hospital for survivors and nonsurvivors combined (Appendix 6). None of the studies found a significant difference between the treatment groups. Shoemaker et al (Shoemaker 1988) reported more days in hospital for all groups compared with other studies of high-risk surgery patients.

\section{Hospital LOS: general ICU studies}

Two studies (Harvey 2005; Richard 2003) with a total of 1689 patients reported the mean (standard deviation) LOS in hospital. Pooled data gave a MD in days spent in hospital of $-0.80(95 \% \mathrm{Cl}$ -2.71 to 1.12 ) comparing management with a PAC to management without a PAC (heterogeneity $\mathrm{Tau}^{2}=0.34 ; \mathrm{Chi}^{2}=1.09, \mathrm{df}=1(\mathrm{P}=$ 0.30); $I^{2}=9 \%$ ) (Analysis 4.1; Appendix 6).

\section{Hospital LOS: high-risk surgery studies}

Five studies with a total of 503 patients reported hospital LOS. Four (Bender 1997; Berlauk 1991; Shoemaker 1988; Valentine 1998) of them were preoperative optimizations and one (Isaacson 1990) was a study of perioperative monitoring, reporting the mean (standard deviation) LOS in hospital. Pooled data gave a MD in days spent in hospital of $0.35(95 \% \mathrm{Cl}-0.05$ to 0.75$)$ comparing management with and without a PAC (heterogeneity $\mathrm{Tau}^{2}=0.00 ; \mathrm{Chi}^{2}=3.54, \mathrm{df}=$ $\left.4,(P=0.47) ; I^{2}=0 \%\right)$. For two studies, which had two PAC groups, a weighted mean (and standard deviation (SD)) hospital LOS was used (Berlauk 1991; Shoemaker 1988) (Analysis 4.2).

\section{Cost}

Four studies (Berlauk 1991; Isaacson 1990; Pearson 1989; Shoemaker 1988), all conducted in the US, collected data on costs of care based on hospital charges (Appendix 7) (the units shown are 1000 USD). Pearson et al (Pearson 1989) used the mean of the total cost, which was the amount actually billed to the patient. Information was also given about specific costs of arterial blood gas measurement, cardiac output measurements, and measurement of haemoglobin and haematocrit. Only the total costs have been included in this review. They reported that the mean costs per patient were significantly higher for the mixed venous oxygen saturation $\left(\mathrm{SvO}_{2}\right)$ PAC group compared with the standard PAC group, although the $P$ value was not given. The costs given in the table (Appendix 7) for the control group excluded the 46 patients reassigned after randomization, which were as follows: reassigned to management with standard PAC $(n=33)$, mean total cost (SD) USD 986 (578) (USD 1068.28 for 2011, Cochrane cost converter); reassigned to management with $\mathrm{SvO}_{2}$ PAC $(n=13)$, mean total cost (SD) USD 1126 (382) (USD 1219.97 for 2011, Cochrane cost converter). In addition to the hospital charges, Isaacson et al (Isaacson 1990) reported the professional fees charged by the anaesthesiologists per patient in each group and found that the fees were significantly higher per patient in the PAC group $(P=$ 0.0001 ) compared with the control group.

For the meta-analysis, it was not appropriate to combine hospital costs with physician costs as there are physician charges specifically for insertion of a PAC. We excluded two studies from the subgroup analysis: the study by Pearson et al (Pearson 1989), for reasons described earlier, and the study by Shoemaker et al (Shoemaker 1988) because the SD was not reported. Therefore, data from two studies with a total of 191 patients (Berlauk 1991; Isaacson 1990) that reported hospital costs were combined with a fixed-effect model (MD 0.90, 95\% Cl -2.62 to 4.42) (Analysis 5.1).

\section{DISCUSSION}

\section{Summary of main results}

We identified 13 RCTs with 5686 patients assessing mortality, hospital and ICU LOS and cost effectiveness of PAC in ICUs (Summary of findings for the main comparison). Five of these studies investigated the clinical effectiveness of PACs in the management of general intensive care patients. The remaining eight studies studied high-risk surgical patients. Of these surgical patients, five trials investigated whether preoperative optimization of haemodynamics improved patient outcomes (Bender 1997; Berlauk 1991; Sandham 2003; Shoemaker 1988; Valentine 1998). In these studies, placement of a PAC was part of a package of care that also included admission to ICU preoperatively and optimization of haemodynamics to predetermined goals. Because patients admitted to ICU are a heterogeneous group, we performed subgroup analysis for studies of elective highrisk surgery patients (perioperative monitoring with and without preoperative optimization) and studies of general intensive care patients. Studies which had the potential for some aspects of high risk of bias had low weight due to small numbers of patients and were included because of their limited effect on the meta-analyses.

We could not demonstrate any beneficial or harmful effects of PACs on mortality, hospital LOS and cost of care in either patients in general ICUs or a subgroup of high-risk surgical patients. Pulmonary artery catheterization did not affect ICU LOS in general intensive care unit patients (reported by four studies) or hospital LOS (reported by nine studies).

A subgroup meta-analysis of five preoperative surgical studies suggested that preoperative optimization guided by a PAC did not improve or worsen the outcome in patients undergoing high-risk surgery. This meta-analysis was heavily weighted ( $85.5 \%$ weight) by the Sandham et al study (Sandham 2003) as this was the largest RCT and had low risk for bias. Sensitivity analysis did not change the mortality results. The overall mortality outcome was similar in both the PAC group and the CVC group.

Four US based studies demonstrated that the overall hospital cost billed for the PAC group was higher than for the CVC group. Two of these studies qualified for analysis and did not show statistically significant hospital cost differences.

\section{Overall completeness and applicability of evidence}

The review question is 'Does the use of PAC in ICUs lead to increased mortality, hospital or ICU LOS and cost?'. PAC is a diagnostic and monitoring tool, not a treatment intervention for any given clinical condition. Use of PAC does not increase or decrease mortality, ICU LOS or hospital LOS. It is appropriate to use in selected patients, by intensive care physicians, as a diagnostic and monitoring tool to guide patient care decisions. Cost effectiveness varies among countries with different healthcare systems. Our analysis on cost cannot be generalized or applied widely. This current evidence is a complete review of all available RCTs to date. It is unlikely that a large prospective RCT comparing PAC with CVC will be 
published in the future. There are several less invasive methods of haemodynamic monitoring, and their comparison with PAC is beyond the scope of this review. Regardless, the applicability of this evidence of no effect on mortality is strong in the ICUs. A PAC is however a diagnostic tool and its impact on management must not be interpreted with regard to mortality outcomes in adults in intensive care. Shock reversal, improvement in organ dysfunction and less vasopressor use are other potential outcome measures that need to be studied.

\section{Barriers in evaluation of the PAC}

One of the main barriers to an effective evaluation of the PAC in intensive care has been the lack of equipoise amongst intensive care clinicians. The training, expertise in PAC measurements, utilization of PAC data for clinical decisions and management of patients vary widely among clinicians. Iberti et al found that providers have significant gaps in their knowledge and expertise in utilizing PAC data (Iberti 1990; Iberti 1994). He reported, from a study done in US and Canada, that the physician's knowledge, understanding, use and interpretation of PAC data were $67 \%$ correct, with a range of $19 \%$ to $100 \%$. Mean scores varied by training, frequency of insertion and use of PAC data in patient treatment (Iberti 1990). Among nurses the test scores of knowledge and use of PAC were associated with years of experience in critical care, critical care registered nurse certification, responsibility for repositioning and manipulating the catheter, frequency of use, and self-assessed adequacy of knowledge (Iberti 1994). A similar study done in Australia utilizing the same questionnaire also found that the test scores were significantly associated with years of experience in intensive care, number of PACs inserted and the physician's certification (Johnston 2008).

The evidence is clear that physicians' and nurses' understanding of PAC and its utility vary widely, making credentialing policies and competency assessments essential. Lack of clinical expertise using PACs may have played a role in patient outcomes in our metaanalysis.

\section{Use of the PAC in clinical practice}

The PAC has been used in various clinical settings and our study did not address its use in cardiac catheterization laboratories, coronary care units or in cardiac pacing. One important use of the PAC is to differentiate various types of shock and to guide therapy. The objective of our analysis was not provider satisfaction, knowledge and comfort level on using PAC; however, these are important considerations in utilizing a diagnostic tool for accomplishing clinically significant results. Lack of any significant mortality improvement from PAC use can be attributed to several factors. A diagnostic and monitoring device that has no therapeutic applications cannot modify outcomes unless the information gathered is utilized appropriately. The aforementioned studies on physicians' and nurses' knowledge on PAC and its applicability, correct interpretation of waveforms, effective utilization of the measured and derived data, and management strategies based on the information gathered vary widely. The significant decline in the clinical utility of PAC in recent years may have caused poor training and expertise, which could lead to occasional delayed utility during the terminal stages of the disease process and improper interpretation (Weiner 2007). Proper use of a PAC depends upon a thorough understanding of factors contributing to measurement errors and data interpretation. The PAC provides a wealth of potentially useful haemodynamic information to the clinicians, and it is only if this information is utilized correctly that it may be helpful in patient management (Evans 2009).

\section{Advantages of the PAC}

During current clinical practice many clinicians still seek haemodynamic data to manage critically ill patients. For this reason, a variety of non-invasive monitoring devices have been introduced and compared with PAC as the reference standard to evaluate the test performance. PACs allow measurement of haemodynamic variables that cannot be measured reliably or continuously by less invasive monitoring devices (Evans 2009). The PAC has the added benefit of being useful as a multilumen infusion port, in addition to its utilization as a monitoring and datagathering device. Critically ill patients require multiple drips and the current standard of practice is to provide central venous access using a CVC. A PAC is also placed through a central access and shares the same short-term complications related to line insertion; however, it has several advantages in addition to intracardiac monitoring. Newer versions of PACs (for example Swan-Ganz flowdirected catheters) provide rapid and effective monitoring of right heart pressures and have the capability to measure mixed venous oxygen saturation, perform cardiac pacing, and to assess the pulmonary vasculature by injecting contrast media to do selective angiographic studies (Edwards Lifesciences 2012). The studies included in our analysis used a standard PAC.

The PAC also has a pivotal role in the measurement of central venous oxygen saturation $\left(\mathrm{ScVO}_{2}\right)$. The measurement of $\mathrm{ScVO}_{2}$ is crucial in the management of patients with severe sepsis and septic shock (Rivers 2001). $\mathrm{ScVO}_{2}$ is obtained through the measurement of oxygen saturation in venous blood returning to the heart and is representative of the balance between oxygen delivery and consumption. A recent study showed that both low and high $\mathrm{ScVO}_{2}$ values obtained in the emergency department were associated with increased mortality in sepsis patients (Pope 2010) thus underlining the importance of continuous ScVO2 monitoring via either a PAC or $\mathrm{ScVO}_{2}$ catheter.

\section{Quality of the evidence}

The quality of evidence from this review for the mortality outcome in this population is robust. Using the Cochrane Grades of Recommendation, Assessment, Development, and Evaluation (GRADE) approach, the evidence was high for hospital and ICU LOS but was low for cost analysis. Only RCTs were included in the meta-analysis but many observational studies, meta-analyses and systematic reviews, cohort studies, and grey literature were examined as sources to identify RCTs. A complete risk of bias analysis and sensitivity analysis minimized uncertainties and provided concrete evidence based support. We had limitations in analysing the secondary outcomes (hospital LOS, ICU LOS and cost) because only some of the studies reported them. This was particularly so for cost effectiveness, which was reported in four studies. We performed subgroup analysis for general intensive care patients and high-risk surgical patients, and the results did not vary significantly. Overall, the internal validity and quality of evidence is high (Summary of findings for the main comparison). 


\section{Potential biases in the review process}

One potential bias is the fact that this is an update from a previous review and may have been influenced by previous conclusions. Another source of bias may be that the two groups of review authors are from the same institution and may have similar backgrounds. To overcome these potential biases four authors (SH, DY, WB and $\mathrm{KR}$ ) from the original review participated in the update. We did not include studies that used PAC in other areas such as in heart failure patients and coronary care units due to the inclusion criteria and the different primary end points in the studies, but we have included these details in the discussion.

\section{Agreements and disagreements with other studies or reviews}

\section{Evaluation of the clinical effectiveness of the PAC}

Evaluation of the clinical effectiveness of managing general intensive care patients with a PAC was addressed by the Fluid and Catheter Treatment Trial (FACTT) (NHLBI 2006) and Pac-Man studies (Harvey 2005); both are major clinical trials with relatively low risks of bias. Both trials were adequately powered multicentre RCTs with over 1000 patients each, in North America and Europe (USA, Canada and UK). Their data on harms or complications of PAC have been conflicting. The results of the FACTT suggested an increased rate of complications from PAC insertion, as opposed to the Pac-Man study which concluded no harm from PAC insertion. The results do, however, agree with the findings of previous smaller studies (Guyatt 1991; Rhodes 2002; Richard 2003) that PACs do not appear to confer survival advantage, nor do they reduce hospital length of stay or costs of care. Both these trials disagreed with the excess mortality findings reported by Connors et al (Connors 1996) and showed that management with a PAC did not worsen the outcome in critically ill patients.

\section{Evaluation of efficacy of the PAC}

FACTT (NHLBI 2006) was the only trial which evaluated the efficacy of the PAC, but it did not address the ongoing debate as to whether the use of a PAC as a diagnostic device and monitoring tool can be responsible for adverse patient outcomes, especially because it is not a therapeutic intervention. One may argue that adverse outcomes may be related to complications of the procedure, but rather they appear to be from inadequate training and skills in utilizing the data and the lack of clinical expertise and approved treatment protocols with the use of a PAC.

\section{PAC monitoring coupled with therapy}

There is mounting evidence for the preemptive strategy of haemodynamic monitoring with a PAC coupled with therapy to reduce surgical mortality and morbidity (Hamilton 2011). Hamilton et al in their systematic review and meta-analysis of 29 trials involving 4805 patients that had perioperative haemodynamic manipulation, which included a PAC with other interventions, reported significantly reduced mortality (OR $0.43,95 \% \mathrm{Cl} 0.33$ to $0.78, \mathrm{P}=0.0002$ ) and surgical complications. Gurgel et.al performed another meta-analysis of studies involving high-risk surgical patients with the use of a PAC to maintain tissue perfusion (Gurgel 2011). This study of 32 RCTs comprising 5056 high-risk surgical patients showed a significant reduction in mortality rate (odds ratio (OR) $0.67,95 \mathrm{Cl} \% 0.55$ to $0.70, \mathrm{P}<0.00001$ ) and postoperative organ dysfunction when a haemodynamic protocol was used to maintain tissue perfusion. Brienza et al published a meta-analysis of 20 studies with 4220 patients and found that perioperative haemodynamic optimization significantly reduced postoperative acute renal injury and the need for renal replacement therapy (Brienza 2009). These studies suggest that haemodynamic monitoring with a PAC and intervention in surgical subgroups of patients have significant clinical value, with improved organ dysfunction and mortality reduction.

\section{Studies in agreement}

A meta-analysis of major morbidities from 12 RCTs involving the use of a PAC showed a very small reduction in morbidity with the PAC (Ivanov 2000). Another meta-analysis that examined the relationship of outcomes and resuscitation therapies showed that in studies of severely ill patients, PAC insertion provided a mortality benefit when haemodynamic optimization was performed prior to organ failure, and that there were no differences in outcomes when the PAC was utilized in less critically ill patients or following the onset of multiorgan failure (Kern 2002). Similar results were reported in a meta-analysis by Shah et al that used wider inclusion criteria for studies including heart failure patients (mortality OR $1.04,95 \% \mathrm{Cl} 0.9$ to 1.2 ; and hospital LOS MD 0.11 days, $95 \% \mathrm{Cl}-0.51$ to 0.74 ) (Shah 2005). Two RCTs included in the Shah meta-analysis were studies of perioperative monitoring. One study showed no difference in mortality (Bonazzi 2002) and the other study showed a significant reduction in mortality (2.9\% in PAC group versus $29 \%$ in controls) (Schultz 1985). The ESCAPE trial had advanced heart failure patients who were admitted to coronary care units and the therapeutic goals were different, looking at the days alive out of hospital during the first six months, quality of life, biochemical and echocardiographic changes (ESCAPE 2005). These studies also concluded that PAC use did not change the overall mortality.

\section{Cost effectiveness}

Four of the 13 studies included a cost component based on hospital charges to patients, and were conducted in US hospitals. One of the problems with this approach is that specific charges vary across hospitals, and patients may not be charged the same for the cost of daily monitoring with a PAC. All the studies reported that, on average, total costs were higher for patients managed with PACs compared with those managed without. The cost effectiveness evaluation for the PAC-Man study (Stevens 2005) provided data based on UK practice. The primary outcome measure was qualityadjusted life years (QALYs) and the secondary outcome measure was hospital mortality. The authors concluded that withdrawal of PACs from routine clinical use in ICUs within the NHS may be considered cost effective. These cost effectiveness analyses of a PAC compared to CVC cannot be broadly applied to the current clinical practice. Cost varies across countries, regions, healthcare systems and types of catheters used. Cost effectiveness cannot be generalized to different populations, particularly for medical and surgical patients.

\section{Other haemodynamic monitoring devices}

Clinicians are still looking for haemodynamic monitoring tools without the known complications of the PAC. Newer cardiac output catheters are already being used in ICUs to provide haemodynamic measurements based on arterial contour power and pulse power analyses. The examples of catheters which use a different calibration scheme for measurement of cardiac output (CO) are the lithium indicator dilution calibration system 
(LiDCO plus ${ }^{T M}$ ), which uses a transthoracic lithium dilution estimate of cardiac output (CO) for calibration; PiCCO plus TM uses trans-thoracic thermodilution differences in arterial compliance; whereas flow Trac ${ }^{\top M}$ calculates $\mathrm{CO}$ from the pulse contour using a proprietary algorithm (Hadian 2007). These catheters cannot be used as infusion ports, available with the PAC. These catheters are preferably inserted into a large calibre artery like the femoral artery, which is again invasive and associated with complications, and are attached to monitors which perform arterial power analysis and pulse power analysis. The need for frequent recalibration is a potential disadvantage of these newer techniques. These techniques of measurement are relatively new and will require validation in comparison to PAC in large-scale randomized trials for their effectiveness in therapy in ICUs.

\section{AUTHORS' CONCLUSIONS}

\section{Implications for practice}

This review concentrated specifically on patients admitted to ICUs. This meta-analysis concluded that use of a PAC alone, without a properly designed therapeutic strategy based on haemodynamic data, did not affect mortality, ICU LOS, hospital LOS or cost in adult ICUs. It is important to note that the PAC itself is a diagnostic and haemodynamic monitoring tool and not a therapeutic intervention to achieve any major clinical outcomes. It is not a harmful tool and may be used successfully for diagnostic and haemodynamic monitoring in ICU patients by highly trained specialists (critical care physicians, cardiologists, anaesthesiologists) with appropriate training in interpretation of the PAC variables, and its applicability in specific clinical scenarios has been shown in recent studies of surgical patients.

\section{Implications for research}

Efficacy studies are needed to determine if there are optimal, PACguided management protocols which, when applied to specific patient groups in ICUs, could result in benefit. Shock reversal, improved organ dysfunction and vasopressor use are other potential outcome measures that need to be studied. In high-risk surgical patients, preemptive haemodynamic monitoring with PAC coupled with therapy has shown significant reduction in mortality and organ dysfunction (for example improved renal function) in recent meta-analyses ( Brienza 2009; Gurgel 2011; Hamilton 2011).

One of the reasons that PAC use in general ICUs has been diminishing in recent years may be due to the increased availability of sophisticated and less invasive devices to monitor cardiac output. These are devices based on trans-oesophageal Doppler, lithium dilution, pulse contour analysis, thoracic impedance and carbon dioxide rebreathing. One explanation for the lack of benefit arising from PAC use was that there was no additional survival advantage gained from a more detailed knowledge of haemodynamics, and this was particularly true when there was no protocol driven management strategy associated with that information. Similarly, the new devices need careful scrutiny before they replace the PAC as another unevaluated 'reference standard', especially when they only serve as diagnostic tools.

\section{ACK N O WLEDGEMENTS}

We would like to thank Jane Cracknell for her help and editorial advice during the preparation of this review, Karen Hovhannisyan for the literature search, and the editorial team of the Cochrane Anaesthesia Review Group. We thank Dr Tianjing Li from John Hopkins School of Public Health, Baltimore; and Mary Land for her guidance and editorial help in the review. We would like to thank the original review authors S Harvey, D Young, W Brampton, A Cooper, G Doig, W Sibbald, K Rowan for their contributions to the original review (Harvey 2006). We thank Sankavi Rajaram from the West Windsor-Plainsboro High School South for English language editing.

We would like to thank Anna Lee (content editor); Marialena Trivella (statistical editor); Bernard Allaouchiche, Don Griesdale, Johran Groeneveld (peer reviewers) and Tracey Lloyd (consumer reviewer) for their help and editorial advice during the preparation of this updated systematic review. 


\section{RE F E R E N C E S}

\section{References to studies included in this review}

Bender 1997 \{published data only\}

* Bender JS, Smith-Meek MA, Jones CE. Routine pulmonary artery catheterization does not reduce morbidity and mortality of elective vascular surgery: results of a prospective randomized trial. Annals of Surgery 1997;226(3):229-37. [MEDLINE: 9339929]

\section{Berlauk 1991 \{published data only\}}

* Berlauk JF, Abrams JH, Gilmour IJ, O'Connor R, Knighton DR, Cerra FB. Preoperative optimization of cardiovascular hemodynamics improves outcome in peripheral vascular surgery. A prospective, randomized clinical trial. Annals of Surgery 1991;214(3):289-99. [MEDLINE: 1929610]

\section{Guyatt 1991 \{published data only\}}

* Guyatt G. A randomized control trial of right-heart catheterization in critically ill patients. Ontario Intensive Care Study Group. Journal of Intensive Care Medicine 1991;6(2):91-5. [MEDLINE: 10147952]

\section{Harvey 2005 \{published data only\}}

* Harvey S, Harrison D, Singer M, Ashcroft J, Jones C, Elbourne $D$, et al. An assessment of the clinical effectiveness of pulmonary artery catheters in patient management in intensive care (PAC-Man): a randomised controlled trial. Lancet 2005;366(9484):472-7. [MEDLINE: 16084255]

Isaacson 1990 \{published data only\}

* Isaacson IJ, Lowdon JD, Berry AJ, Smith RB 3d, Knos GB, Weitz Fl, et al. The value of pulmonary artery catheter and central venous monitoring in patients undergoing abdominal aortic reconstructive surgery: a comparative study of two selected, randomized groups. Journal of Vascular Surgery 1990;12(6):754-60. [MEDLINE: 2243411]

\section{Joyce 1990 \{published data only\}}

* Joyce W, Provan JL, Ameli FM, McEwan MM, Jelenich S, Jones DP. The role of central haemodynamic monitoring in abdominal aortic surgery. A prospective randomised study. European Journal of Vascular Surgery 1990;4(6):633-6. [MEDLINE: 2279574]

\section{NHLBI 2006 \{published data only\}}

NHLBI 2006 National Heart, Lung, and Blood Institute Acute Respiratory Distress Syndrome (ARDS) Clinical Trials Network, Wheeler AP, Bernard GR, Thompson BT, Schoenfeld D, Wiedemann HP, deBoisblanc B, et al. Pulmonary-artery versus central venous catheter to guide treatment of acute lung injury. The New England Journal of Medicine 2006;354(21):2213-24. [MEDLINE: 16714768]

\section{Pearson 1989 \{published data only\}}

* Pearson KS, Gomez MN, Moyers JR, Carter JG, Tinker JH. A cost/benefit analysis of randomized invasive monitoring for patients undergoing cardiac surgery [see comments]. Anesthesia and Analgesia 1989;69(3):336-41. [MEDLINE: 2505641]
Rhodes 2002 \{published data only\}

* Rhodes A, Cusack RJ, Newman PJ, Grounds M, Bennett D. A randomised, controlled trial of the pulmonary artery catheter in critically ill patients. Intensive Care Medicine 2002;28(3):256-64. [MEDLINE: 11904653]

\section{Richard 2003 \{unpublished data only\}}

* Richard C, Warszawski J, Anguel N, Deye N, Combes A, Barnoud D, et al. Early use of the pulmonary artery catheter and outcomes in patients with shock and acute respiratory distress syndrome: a randomized controlled trial. JAMA 2003;290(20):2713-20. [MEDLINE: 14645314]

Sandham 2003 \{published data only\}

* Sandham JD, Hull RD, Brant RF, Knox L, Pineo GF, Doig CJ, et al. A randomized, controlled trial of the use of pulmonaryartery catheters in high-risk surgical patients. The New England Journal of Medicine 2003;348(1):5-14. [MEDLINE: 12510037]

\section{Shoemaker 1988 \{published data only\}}

* Shoemaker WC, Appel PL Kram HB, Waxman K, Lee TS. Prospective trial of supranormal values of survivors as therapeutic goals in high-risk surgical patients. Chest 1988;94(6):1176-86. [MEDLINE: 3191758]

Valentine 1998 \{published data only\}

* Valentine RJ, Duke ML, Inman MH, Grayburn PA, Hagino RT, Kakish HB, et al. Effectiveness of pulmonary artery catheters in aortic surgery: A randomized trial. Journal of Vascular Surgery 1998;27(2):203-12. [MEDLINE: 9510275]

\section{References to studies excluded from this review}

Bach 1992 \{published data only\}

* Bach A, Bohrer H, Gleiss HK. Safety of a guidewire technique for replacement of pulmonary artery catheters. Journal of Cardiothoracic and Vascular Anesthesia 1992;6:711-4. [MEDLINE: 1472669]

\section{Barone 2001 \{published data only\}}

Barone JE, Tucker JB, Rassias D, Corvo PR. Routine perioperative pulmonary artery catheterization has no effect on rate of complications in vascular surgery: a meta-analysis. The American Surgeon 2001;67:674-9. [MEDLINE: 11450787]

\section{Boldt 1995 \{published data only\}}

* Boldt J, Heesen M, Muller M, Hempelmann G. Continuous monitoring of critical patients with a newly developed pulmonary arterial catheter. A cost analysis. Anaesthetist 1995;44:423-8. [MEDLINE: 7653794]

\section{Bonazzi 2002 \{published data only\}}

* Bonazzi M, Gentile F, Biasi GM, Migliavacca S, Esposti D, Cipolla M, et al. Impact of perioperative haemodynamic monitoring on cardiac morbidity after major vascular surgery in low risk patients. A randomised pilot trial. European Journal of Vascular Surgery 2002;23:445-51. [MEDLINE: 12027474] 


\section{Boyd 1993 \{published data only\}}

* Boyd O, Grounds RM, Bennett ED. A randomized clinical trial of the effect of deliberate perioperative increase of oxygen delivery on mortality in high-risk surgical patients. JAMA 1993;270:2699-707. [MEDLINE: 7907668]

\section{Brazzi 1995 \{published data only\}}

* Brazzi L, Gattioni L, Latini R, Tognoni G. The SvO2 Study: General design and results of the feasibility phase of a multicenter, randomized trial of three different hemodynamic approaches and two monitoring techniques in the treatment of critically ill patients. Controlled Clinical Trials 1995;16:74-87. [MEDLINE: 7743791]

\section{Cobb 1992 \{published data only\}}

* Cobb DK, High KP, Sawyer RG, Sable CA, Adams RB, Lindley DA, et al. A controlled trial of scheduled replacement of central venous and pulmonary artery catheters. The New England Journal of Medicine 1992;327:1062-8. [MEDLINE: 1522842]

\section{Cohen 1998 \{published data only\}}

Cohen Y, Fosse JP, Karoubi P, Reboul-Marty J, Dreyfuss D, Hoang P, et al. The "hands off" catheter and the prevention of systemic infections associated with pulmonary artery catheter: a prospective study. American Journal of Respiratory and Critical Care Medicine 1998;157:284-7. [MEDLINE: 9445311]

\section{Eyer 1990 \{published data only\}}

* Eyer S, Brummitt C, Crossley K, Siegel R, Cerra F. Catheterrelated sepsis: prospective, randomized study of three methods of long-term catheter maintenance. Critical Care Medicine 1990;18:1073-9. [MEDLINE: 2209033]

\section{Girbes 1999 \{published data only\}}

* Girbes AR, Ligtenberg JJ, Sonneveld JP, Wierda JM. Prevention of hypotension after induction of anesthesia after preoperative tune-up. A preliminary report of the Groningen Tune-up Study. Netherlands Journal of Medicine 1999;54:213-4. [MEDLINE: 10399449]

\section{Holmes 1997 \{published data only\}}

* Holmes DR Jr, Califf RM, Van de Werf F, Berger PB, Bates ER, Simoons ML, et al. Difference in countries' use of resources and clinical outcome for patients with cardiogenic shock after myocardial infarction: results from the GUSTO trial. Lancet 1997;349:75-8. [MEDLINE: 8996417]

\section{Kearns 1993 \{published data only\}}

Kearns PJ. A controlled trial of scheduled replacement of central venous and pulmonary catheters. Journal of Parenteral and Enteral Nutrition 1993;17:292. [MEDLINE: 8505839]

\section{Latour-Perez 1997 \{published data only\}}

* Latour-Perez J, Calvo-Embuena R. Evaluation of the use of the pulmonary artery catheter in patients with acute myocardial infarct: the PAEEC study. Project of the Epidemiologic Analysis of Critical Illness. Medicina Clínica 1998;110:721-6. [MEDLINE: 9672864]
Mermel 1991 \{published data only\}

Mermel LA, McCormick RD, Springman SR, Maki DG. The pathogenesis and epidemiology of catheter-related infection with pulmonary artery Swan-Ganz catheters: a prospective study utilizing molecular subtyping. The American Journal of Medicine 1991;91:197S-205S. [MEDLINE: 1928165]

Mitchell 1992 \{published data only\}

* Mitchell JP, Schuller D, Calandrino FS, Schuster. Improved outcome based on fluid management in critically ill patients requiring pulmonary artery catheterization. The American Review of Respiratory Disease 1992;145:990-8. [MEDLINE: 1586077]

Orlando 1985 \{published data only\}

* Orlando R, Nelson LD, Civetta JM. Invasive pre-operative evaluation of high-risk patients. Critical Care Medicine 1985;13:26.

Raybin 1989 \{published data only\}

* Raybin DM. Pulmonary artery catheterization. Chest 1989;96:957. [MEDLINE: 2676400]

Schultz 1985 \{published data only\}

* Schultz RJ, Whitfield GF, LaMura JJ, Raciti A, Krishnamurthy S. The role of physiologic monitoring in patients with fractures of the hip. The Journal of Trauma 1985;25:309-16. [MEDLINE: 3989888]

Senagore 1987 \{published data only\}

* Senagore A, Waller JD, Bonnell BW, Bursch LR, Scholten DJ. Pulmonary artery catheterization: a prospective study of internal jugular and subclavian approaches. Critical Care Medicine 1987;15:35-7. [MEDLINE: 3539524]

Shoemaker 1990 \{published data only\}

* Shoemaker WC, Kram HB, Appel PL, Fleming AW. The efficacy of central venous and pulmonary artery catheters and therapy based upon them reducing mortality and morbidity. Archives in Surgery 1990;125:1332-7. [MEDLINE: 2222172]

Sola 1993 \{published data only\}

* Sola JE, Bender JS. Use of the pulmonary artery catheter to reduce operative complications. The Surgical Clinics of North America 1993;73:253-64. [MEDLINE: 8456356]

\section{Stewart 1998 \{published data only\}}

* Stewart RD, Psyhojos T, Lahey SJ, Levitsky S, Campos CT. Central venous catheter use in low-risk coronary artery bypass grafting. The Annuals of Thoracic Surgery 1998;66:1306-11. [MEDLINE: 9800825]

\section{Stout 2006 \{published data only\}}

Stout CL, Van de Water JM, Thompson WM, Bowers EW, Sheppard, S.W, Tewari AM, et al. Impedance cardiography: can it replace thermodilution and the pulmonary artery catheter?. American Surgeon. 2006;72(8):728-32, discussion 733-4.

\section{Stubbig 1992 \{published data only\}}

* Bach A, Stubbig K, Geiss HK. Infectious risk of replacing venous catheters by the guide-wire technique. Zentralblatt 
für Hygiene und Umweltmedizin 1992;193:150-9. [MEDLINE: 1388616]

\section{Suttner 2006 \{published data only\}}

Suttner A, Schollhorn T, Boldt J, Mayer J, Rohm J, Lang K, et al. Non invasive assessment of cardiac output using thoracic electrical bioimpedence in hemodynamically stable and unstable patients after cardiac surgery: a comparison with pulmonary artery thermodilution. Intensive Care Medicine 2006;32:2053-8. [DOI: 10.1007/s00134-006-0409-x]

Takala 2011 \{published data only\}

Takala J, Ruokonen E, Tenhunen JJ, Parviainen I, Jakob SM. Early non-invasive cardiac output monitoring in hemodynamically unstable intensive care patients: A multicenter randomized controlled trial. Critical Care 2011;15:R148.

\section{Tuman 1989 \{published data only\}}

* Tuman KJ, McCarthy RJ, Spiess BD, DaValle M, Hompland SJ, Dabir R, et al. Effect of pulmonary artery catheterization on outcome in patients undergoing coronary artery surgery. Anesthesiology 1989;70:199-206. [MEDLINE: 2913857]

\section{Wilson 1999 \{published data only\}}

* Wilson J, Woods I, Fawcett J, Whall R, Dibb W, Morris C, et al. Reducing the risk of major elective surgery: randomised controlled trial of preoperative optimisation of oxygen delivery. BMJ 1999;318:1099-103. [MEDLINE: 10213716]

\section{Yu 1993 \{published data only\}}

* Yu M, Levy MM, Smith P, Takiguchi SA, Miyasaki A, Myers SA. Effect of maximizing oxygen delivery on morbidity and mortality rates in critically ill patients: a prospective, randomized, controlled trial. Critical Care Medicine 1993;21:830-8. [MEDLINE: 8504649]

\section{Yu 1995 \{published data only\}}

* Yu M, Takanishi D, Myers SA, Takiguchi SA, Severino R, Hasaniya N, et al. Frequency of mortality and myocardial infarction during maximizing oxygen delivery: a prospective, randomized trial. Critical Care Medicine 1995;23:1025-32. [MEDLINE: 7774212]

\section{Yu 2011 \{published data only\}}

YuM, Pei K, Moran S, Edwards KD, Domingo S, Steinemann S, et al. A prospective randomized trial using blood volume analysis in addition to pulmonary artery catheter, compared with pulmonary artery catheter alone, to guide shock resuscitation in critically ill surgical patients. Shock (Augusta, Ga.) 2011;35(3):220-8

\section{Ziegler 1997 \{published data only\}}

* Ziegler DW, Wright JG, Choban PS, Flancbaum L. A prospective randomized trial of preoperative "optimization" of cardiac function in patients undergoing elective peripheral vascular surgery. Surgery 1997;122:584-92. [MEDLINE: 9308617]

\section{Additional references}

\section{ASA task force on PAC 2003}

American Society of Anesthesiologists Task Force on Pulmonary Artery Catheterization. Practice guidelines for pulmonary artery catheterization: an updated report by the American Society of Anesthesiologists Task Force on Pulmonary Artery Catheterization. Anesthesiology 2003 Oct;99(4):988-1014. [MEDLINE: 14508336]

\section{Assoc. Press 1996}

Associated Press. Heart monitoring system may kill some patients. The Dallas Morning News 1996; Vol. Sept 18.

\section{Binanay 2005}

Binanay C, Califf RM, Hasselblad V, O'Connor CM, Shah MR, Sopko G. Evaluation study of congestive heart failure and pulmonary artery catheterization effectiveness: the ESCAPE trial. JAMA 2005;294:1693-4. [MEDLINE: 16204662]

\section{Brienza 2009}

Brienza N, Giglio MT, Marucci M, Fiore T. Does perioperative hemodynamic optimization protect renal function in surgical patients? A meta-analytic study. Critical Care Medicine 2009;37(6):2079-90. [PUBMED: 19384211]

\section{Chatterjee 2009}

Chatterjee K. The Swan-Ganz catheters: past, present, and future. A viewpoint. Circulation 2009;119:147-52. [MEDLINE: 19124674]

\section{Cochrane cost converter [Computer program]}

The Campbell and Cochrane Economics Methods Group. The CCEMG-EPPI-Centre cost converter. Version 1.2. The Campbell and Cochrane Economics Methods Group, http://eppi.ioe.ac.uk/ costconversion/default.aspx.

\section{Connors 1996}

Connors AF, Speroff TS, Dawson NV, Thomas C, Harell FE, Wagner $D$, et al. The effectiveness of right heart catheterization in the initial care of critically ill patients. JAMA 1996;276:889-97. [MEDLINE: 8782638]

\section{Cooper 1996}

Cooper AB, Doig GS, Sibbald WJ. Pulmonary artery catheters in the critically ill. Critical Care Clinics 1996;12:777-93. [MEDLINE: 8902371]

\section{Edwards Lifesciences 2012}

(c) 2012 Edwards Lifesciences LLC. Swan-Ganz catheters, Monitoring catheters and Pulmonary Angiography catheters. http://www.edwards.com/products/pacatheters/pages/ monitoringcatheters.aspx Down loaded on April 11, 2012. [on line version]

\section{ESCAPE 2005}

The ESCAPE Investigators and ESCAPE Study Coordinators. Evaluation Study of Congestive Heart Failure and Pulmonary Artery Catheterization Effectiveness [The ESCAPE Trial]. JAMA 2005;294(13):1625-33. 


\section{ESICM 1991}

European Society of Intensive Care Medicine. Expert panel: the use of the pulmonary artery catheter. Intensive Care Medicine 1991;17(3):I-VIII. [MEDLINE: 2071758]

\section{Evans 2009}

Evans DC, Doraiswamy VA, Prosciak MP, Silviera M, Seamon MJ, Rodriguez Funes V, et al. Complications associated with pulmonary artery catheters: A comprehensive clinical review. Scandinavian Journal of Surgery 2009;98:199-208. [MEDLINE: 20218415]

\section{Gattinoni 1995}

Gattinoni L, Brazzi L, Pelosi P, Latini R, Tognoni G, Pesenti A, et al. A trial of goal orientated hemodynamic therapy in critically ill patients.SvO2 Collaborative Group. The New England Journal of Medicine 1995;333:1025-32. [MEDLINE: 7675044]

\section{Gore 1987}

Gore JM, Goldberg RJ, Spodick DH, Alpert JS, Dalen JE. A community-wide assessment of the use of pulmonary artery catheters in patients with acute myocardial infarction. Chest 1987;92:721-7. [MEDLINE: 3652758]

\section{Greenberg 2009}

Greenberg SB, Murphy GS, Vender JS. Current use of the pulmonary artery catheter. Current Opinion in Critical Care 2009;15(3):249-53. [MEDLINE: 19387340 ]

\section{Gurgel 2011}

Gurgel ST, do Nascimento P Jr. Maintaining tissue perfusion in high-risk surgical patients: a systematic review of randomized clinical trials. Anesthesia and Analgesia 2011;112(6):1384-91. [MEDLINE: 21156979.]

\section{Hadian 2007}

Hadian M, Pinsky MR. Functional hemodynamic monitoring. Current Opinion in Critical Care 2007;13(3):318-23. [MEDLINE: 17468565.]

\section{Hamilton 2011}

Hamilton MA, Cecconi M, Rhodes A. A systematic review and meta-analysis on the use of preemptive hemodynamic intervention to improve postoperative outcomes in moderate and high-risk surgical patients. Anesthesia and Analgesia 2011;112(6):1392-402. [MEDLINE: 20966436]

\section{Higgins 2011}

Higgins JPT, Green S, editors. Cochrane Handbook for Systematic Reviews of Interventions 5.1.0 [updated March 2011]. In: The Cochrane Library, 2011 Chichester, UK: John Wiley \& Sons, Ltd.

\section{Iberti 1990}

Iberti TJ, Fischer EP, Leibowitz AB, Panacek EA, Silverstein JH, Albertson TE. A multicenter study of physicians' knowledge of the pulmonary artery catheter. Pulmonary Artery Catheter Study Group. JAMA 1990;264(22):2928-32. [MEDLINE: 2232089]

\section{Iberti 1994}

Iberti TJ, Daily EK, Leibowitz AB, Schecter CB, Fischer EP, Silverstein JH. Assessment of critical care nurses' knowledge of the pulmonary artery catheter. The Pulmonary Artery Catheter Study Group. Critical Care Medicine 1994 Oct;22(10):1674-8. [MEDLINE: 7924381]

\section{Ivanov 2000}

Ivanov R, Allen J, Calvin J. The incidence of major morbidity in critically ill patients managed with pulmonary artery catheters: a meta-analysis. Critical Care Medicine 2000;28:615-9. [MEDLINE: 10752803]

\section{Johnston 2008}

Johnston IG, Fraser JF, Sabapathy S, Kruger PS. The pulmonary artery catheter in Australasia: a survey investigating intensive care physicians' knowledge and perception of future trends in use. Anaesthesia and Intensive Care 2008;36(1):84-9. [MEDLINE: 18326138]

\section{Kern 2002}

Kern JW, Shoemaker WC. Meta-analysis of hemodynamic optimization in high-risk patients. Critical Care Medicine 2002 Aug;30(8):1686-92. [MEDLINE: 12163777]

\section{Lamperti 2012}

Lamperti M, Bodenham AR, Pittiruti M, Blaivas M, Augoustides JG, Elbarbary M, et al. International evidencebased recommendations on ultrasound-guided vascular access. Intensive Care Medicine 2012;38:1105-17. [DOI : 10.1007/ s00134-012-2597-x]

\section{PAC Consensus 1997}

Pulmonary Artery Catheter Consensus Conference Participants. Pulmonary Artery Catheter Consensus Statement. Critical Care Medicine 1997;25:910-25. [MEDLINE: 9201042]

\section{Pope 2010}

Pope JV, Jone AE, Gaieski DF, Arnold RC, Trzeciak S, Sharpiro NI. Multicenter study of central venous oxygen saturation (ScVO2) as a predictor of mortality in patients with sepsis. Annals of Emergency Medicine 2010;55:40-6. [MEDLINE: 19854541]

\section{RevMan 5.1 [Computer program]}

Copenhagen: The Nordic Cochrane Centre, The Cochrane Collaboration. Review Manager (RevMan) [Computer program]. Version 5.1 for Windows Copenhagen. The Cochrane Collaboration 2011. Copenhagen: The Nordic Cochrane Centre, The Cochrane Collaboration, 2011.

\section{Rivers 2001}

Rivers E, Nguyen B, Havstad S, et al. Early goal-directed therapy in the treatment of severe sepsis and septic shock. The New England Journal of Medicine 2001;345:1368-77. [MEDLINE: 11794169]

\section{Shah 2005}

Shah MR, Hasselblad V, Stevenson LW, Binanay C, O'Connor CM, Sopko G, et al. Impact of pulmonary artery catheter in critically ill patients. Meta-analysis of randomized clinical trials. JAMA 2005;294:1664-70. [MEDLINE: 16204662] 


\section{Stevens 2005}

Stevens K, McCabe C, Jones C, Ashcroft J, Harvey S, Rowan K, on behalf of the PacMan Study Collaboration. The incremental cost effectiveness of withdrawing pulmonary artery catheters from routine use in critical care. The incremental cost effectiveness of withdrawing pulmonary artery catheters from routine use in critical care. Applied Health Economics and Health Policy 2005;4:257-64. [MEDLINE: 16466277]

\section{Swan 1970}

Swan HJ, Ganz W, Forrester J, Marcus H, Diiamond G, Chonette D. Catheterization of the heart in man with use of flow-directed balloon-tipped catheter. New England Journal of Medicine 1970;283:447-51. [MEDLINE: 5434111]

\section{Weiner 2007}

Wiener B, Chacko S, Cron SG, Cohen MZ. Guideline development and education to insure accurate and consistent pulmonary artery wedge pressure measurement by nurses in intensive care units. Dimensions of Critical Care Nursing 2007;26(6):263-8. [MEDLINE: 18090148]

\section{Wiener 2007}

Wiener RS, Welch HG. Trends in the use of the pulmonary artery catheter in the United States, 1993-2004. JAMA 2007;298(4):423-9. [MEDLINE: 17652296]

\section{Zion 1990}

Zion MM, Balkin J, Rosenmann D, Goldbourt U, Reicher-Reiss H, Kaplinsky E, et al. Use of pulmonary artery catheters in patients with acute myocardial infarction. Analysis of experience in 5,841 patients in the SPRINT Registry. SPRINT Study Group. Chest 1990;98(6):1331-5. [MEDLINE: 2245670]

\section{References to other published versions of this review Harvey 2006}

Harvey S, Young D, Brampton W, Cooper A, Doig GS, Sibbald W, et al. Pulmonary artery catheters for adult patients in intensive care. Cochrane Database of Systematic Reviews 2006, Issue 3. [DOI: 10.1002/14651858.CD003408.pub2]

* Indicates the major publication for the study

\section{CHARACTERISTICS OF STUDIES}

\section{Characteristics of included studies [ordered by year of study]}

Shoemaker 1988

Methods Randomized by cards arranged according to random numbers tables, by an outside person, placed in sealed opaque envelopes opened in sequence.

Participants

Entry criteria:

patients with one or more of 11 high risk criteria previously defined and associated with a mortality rate close to $30 \%$.

Exclusion criteria: none stated.

Interventions
nAC standard group $(n=30)$ - transfer to ICU. PAC placed followed by standard management to achieve
PAC protocol group $(n=28)$ - transfer to ICU, PAC placed followed by treatment to achieve supra-nor-
mal haemodynamic and oxygen transport values.
Control group $(n=30)-$ CVC placed. Standard care. Not reported if managed in ICU preoperatively

Outcomes Mortality and morbidity (statistic not specified). Main outcome not stated. Also reported ICU and hospital LOS.

Notes

\section{Risk of bias}

\begin{tabular}{lll}
\hline Bias & Authors' judgement & Support for judgement \\
\hline $\begin{array}{ll}\text { Random sequence genera- } \\
\text { tion (selection bias) }\end{array}$ & High risk & $\begin{array}{l}\text { Two series of patients in both groups and number of patients were not ran- } \\
\text { domized. Series one randomization was not clear, series 2, some patients were } \\
\text { randomized postoperatively, some preoperatively and some are not random- } \\
\text { ized. }\end{array}$
\end{tabular}


Shoemaker 1988 (Continued)

$\begin{array}{ll}\begin{array}{l}\text { Allocation concealment } \\ \text { (selection bias) }\end{array} & \text { Low risk }\end{array} \quad \begin{aligned} & \text { Designated by cards arranged according to a random number table by an out- } \\ & \text { side person, placed in opaque sealed envelope }\end{aligned}$

\begin{tabular}{|c|c|c|}
\hline $\begin{array}{l}\text { Blinding of participants } \\
\text { and personnel (perfor- } \\
\text { mance bias) } \\
\text { primary outcome }\end{array}$ & High risk & Not blinded, but providers were rotated in both control and treatment groups \\
\hline $\begin{array}{l}\text { Blinding of outcome as- } \\
\text { sessment (detection bias) } \\
\text { primary outcome }\end{array}$ & High risk & Not blinded \\
\hline $\begin{array}{l}\text { Incomplete outcome data } \\
\text { (attrition bias) } \\
\text { alloutcomes }\end{array}$ & Low risk & All outcome data are reported \\
\hline $\begin{array}{l}\text { Selective reporting (re- } \\
\text { porting bias) }\end{array}$ & Low risk & Reported all outcome data \\
\hline Other bias & High risk & $\begin{array}{l}\text { Series } 1 \text { had high-risk surgical patients and series } 1 \text { had low-risk surgical pa- } \\
\text { tients, but when physicians felt some patients were not candidates for invasive } \\
\text { monitoring they were excluded from the study or included postoperatively. }\end{array}$ \\
\hline
\end{tabular}

\section{Pearson 1989}

\begin{tabular}{|c|c|c|}
\hline Methods & \multicolumn{2}{|c|}{ Randomized using a table of random numbers (no other details given). } \\
\hline Participants & \multicolumn{2}{|c|}{$\begin{array}{l}\text { Entry criteria: } \\
\text { scheduled for elective cardiac surgery. } \\
\text { Exclusion criteria: } \\
\text { none given. }\end{array}$} \\
\hline Interventions & \multicolumn{2}{|c|}{$\begin{array}{l}\text { PAC } 1 \text { group }(n=86) \text { - standard PAC placed. } \\
\text { PAC } 2 \text { group }(n=66) \text { - mixed venous oxygen measuring PAC placed. } \\
\text { Control group }(n=74) \text { - CVC placed. }\end{array}$} \\
\hline Outcomes & \multicolumn{2}{|c|}{$\begin{array}{l}\text { ICU mortality } \\
\text { ICU LOS } \\
\text { Costs of care. Main outcome not stated. }\end{array}$} \\
\hline Notes & \multicolumn{2}{|c|}{$\begin{array}{l}\text { Of the } 74 \text { patients randomized to the control group, } 46 \text { were reassigned following randomizations to } \\
\text { one of the PAC groups for "ethical" reasons. }\end{array}$} \\
\hline \multicolumn{3}{|l|}{ Risk of bias } \\
\hline Bias & Authors' judgement & Support for judgement \\
\hline $\begin{array}{l}\text { Random sequence genera- } \\
\text { tion (selection bias) }\end{array}$ & High risk & 46 patients were reassigned to $\mathrm{PAC}$ after randomization \\
\hline $\begin{array}{l}\text { Allocation concealment } \\
\text { (selection bias) }\end{array}$ & Low risk & Used a table of random numbers \\
\hline $\begin{array}{l}\text { Blinding of participants } \\
\text { and personnel (perfor- } \\
\text { mance bias) }\end{array}$ & High risk & Not blinded in fact allowed to change the group after randomizations \\
\hline
\end{tabular}


Pearson 1989 (Continued)

primary outcome

\begin{tabular}{lll}
$\begin{array}{l}\text { Blinding of outcome as- } \\
\text { sessment (detection bias) } \\
\text { primary outcome }\end{array}$ & High risk & No blinding done \\
\hline $\begin{array}{l}\text { Incomplete outcome data } \\
\text { (attrition bias) } \\
\text { alloutcomes }\end{array}$ & Low risk & Reported all the cost, LOS and mortality outcomes \\
\hline $\begin{array}{l}\text { Selective reporting (re- } \\
\text { porting bias) }\end{array}$ & Low risk & None \\
\hline $\begin{array}{l}\text { Other bias } \\
\text { High risk }\end{array}$ & $\begin{array}{l}\text { Additional groups } 4 \text { and } 5 \text { were included due to reassignment of groups after } \\
\text { randomizations can cause unknown bias }\end{array}$
\end{tabular}

Isaacson 1990

\begin{tabular}{ll}
\hline Methods & Randomized using marked cards. \\
\hline Participants & Entry criteria: \\
elective aortic reconstructive surgery. & Exclusion criteria: \\
& uncorrectable coronary artery disease; cor pulmonale; severe heart failure; cardiomyopathy; left ven- \\
tricular ejection fraction less than $40 \% ;$ symptomatic valvular disease; renal failure; severe restric- \\
tive/obstructive pulmonary disease.
\end{tabular}

\begin{tabular}{ll}
\hline Interventions & $\begin{array}{l}\text { PAC group }(\mathrm{n}=49) \text { - PAC placed before induction of general anaesthesia. } \\
\text { Control group }(\mathrm{n}=53) \text { - CVC placed before induction of general anaesthesia. }\end{array}$ \\
\hline Outcomes & Hospital mortality, ICU LOS, hospital LOS, costs of care. Main outcome not stated. \\
\hline Notes &
\end{tabular}

\section{Risk of bias}

\begin{tabular}{lll}
\hline Bias & Authors' judgement & Support for judgement \\
\hline $\begin{array}{l}\text { Random sequence genera- } \\
\text { tion (selection bias) }\end{array}$ & Low risk & Used marked cards, shuffled \\
\hline $\begin{array}{l}\text { Allocation concealment } \\
\text { (selection bias) }\end{array}$ & Low risk & $\begin{array}{l}\text { Used faced down cards and made sure investigator would not know which } \\
\text { monitor patient would receive }\end{array}$ \\
\hline $\begin{array}{l}\text { Blinding of participants } \\
\text { and personnel (perfor- } \\
\text { mance bias) } \\
\text { primary outcome }\end{array}$ & High risk & $\begin{array}{l}\text { Not blinded same group who did the study made the patient care decision as } \\
\text { well }\end{array}$ \\
\hline $\begin{array}{l}\text { Blinding of outcome as- } \\
\text { sessment (detection bias) } \\
\text { primary outcome }\end{array}$ & High risk & Not blinded \\
\hline $\begin{array}{l}\text { Incomplete outcome data } \\
\text { (attrition bias) } \\
\text { alloutcomes }\end{array}$ & Low risk & No missing out come data \\
\hline \hline
\end{tabular}


Isaacson 1990 (Continued)

Selective reporting (re- $\quad$ Low risk $\quad$ Followed prespecified protocol
porting bias)

Other bias Low risk None

\section{Joyce 1990}

\begin{tabular}{ll}
\hline Methods & Preoperative randomization into two groups. \\
\hline Participants & $\begin{array}{l}\text { Entry criteria: } \\
\text { elective infra-renal aortic reconstructive surgery. } \\
\text { Exclusion criteria: } \\
\text { unstable angina; recent myocardial infarction (last } 6 \text { months); left ventricular ejection fraction less } \\
\text { than 50\%. }\end{array}$ \\
\hline Interventions & PAC group $(n=21)$ - PAC placed (no management protocol). \\
\hline Outcomes & Main outcome was postoperative cardiac complications (defined). Also reported 30-day postoperative \\
mortality.
\end{tabular}

\section{Risk of bias}

\begin{tabular}{|c|c|c|}
\hline Bias & Authors' judgement & Support for judgement \\
\hline $\begin{array}{l}\text { Random sequence genera- } \\
\text { tion (selection bias) }\end{array}$ & Low risk & Used "sealed envelope technique" \\
\hline $\begin{array}{l}\text { Allocation concealment } \\
\text { (selection bias) }\end{array}$ & Low risk & Sealed envelopes are concealed allocation \\
\hline $\begin{array}{l}\text { Blinding of participants } \\
\text { and personnel (perfor- } \\
\text { mance bias) } \\
\text { primary outcome }\end{array}$ & Unclear risk & Insufficient information to judge \\
\hline $\begin{array}{l}\text { Blinding of outcome as- } \\
\text { sessment (detection bias) } \\
\text { primary outcome }\end{array}$ & Unclear risk & Insufficient information to judge \\
\hline $\begin{array}{l}\text { Incomplete outcome data } \\
\text { (attrition bias) } \\
\text { alloutcomes }\end{array}$ & Low risk & Reported all data \\
\hline $\begin{array}{l}\text { Selective reporting (re- } \\
\text { porting bias) }\end{array}$ & Low risk & Reported all outcomes \\
\hline Other bias & Low risk & None \\
\hline
\end{tabular}


Guyatt 1991

\section{Methods}

Randomization blocked according to a computer-generated list of random numbers in groups of four for each unit. Participating physicians were not aware of the blocking. Envelopes were prepared in sequential order for each unit and were checked daily.

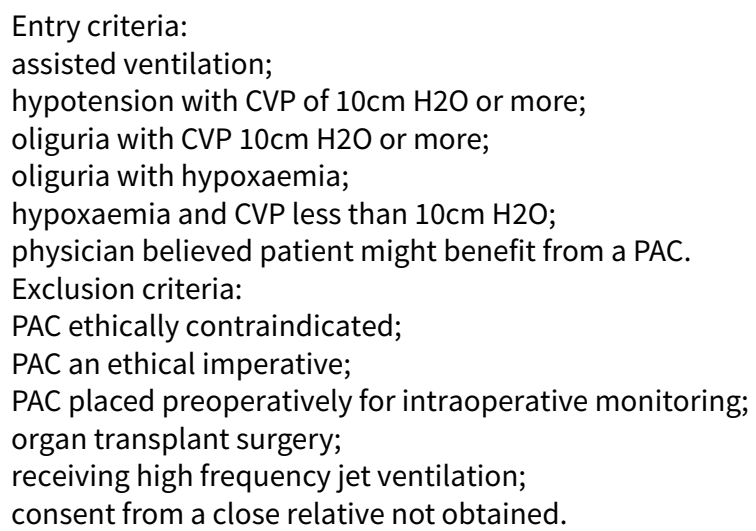

Outcomes Main outcome mortality (mortality statistic not specified). Secondary outcome ICU LOS.

Notes

Trial stopped early because of poor recruitment.

\section{Risk of bias}

\begin{tabular}{|c|c|c|}
\hline Bias & Authors' judgement & Support for judgement \\
\hline $\begin{array}{l}\text { Random sequence genera- } \\
\text { tion (selection bias) }\end{array}$ & Low risk & Computer generated sequence \\
\hline $\begin{array}{l}\text { Allocation concealment } \\
\text { (selection bias) }\end{array}$ & Low risk & Physicians were not aware of blocks and used envelopes \\
\hline $\begin{array}{l}\text { Blinding of participants } \\
\text { and personnel (perfor- } \\
\text { mance bias) } \\
\text { primary outcome }\end{array}$ & High risk & Not blinded and allowed to cross-over to PAC group \\
\hline $\begin{array}{l}\text { Blinding of outcome as- } \\
\text { sessment (detection bias) } \\
\text { primary outcome }\end{array}$ & High risk & $\begin{array}{l}\text { Not blinded and allowed to change the group if physician felt ethically need } \\
\text { PAC }\end{array}$ \\
\hline $\begin{array}{l}\text { Incomplete outcome data } \\
\text { (attrition bias) } \\
\text { alloutcomes }\end{array}$ & Low risk & Reported all data including cross-over data \\
\hline $\begin{array}{l}\text { Selective reporting (re- } \\
\text { porting bias) }\end{array}$ & Low risk & Reported all outcomes \\
\hline Other bias & High risk & $\begin{array}{l}\text { High risk of contaminating the randomized group by allowing the sicker pa- } \\
\text { tients to cross-over to PAC group may have contributed to high mortality re- } \\
\text { ported }\end{array}$ \\
\hline
\end{tabular}


Berlauk 1991

\begin{tabular}{ll} 
Methods & $\begin{array}{l}\text { Randomized using random number generator. Patients entered consecutively in order of appearance } \\
\text { on the surgical schedule. No other details given. }\end{array}$ \\
\hline Participants & $\begin{array}{l}\text { Entry criteria: scheduled to receive an in situ vein graft bypass for lower limb vascular insufficiency. Ex- } \\
\text { clusion criteria: myocardial infarction within } 3 \text { months; coronary artery bypass graft within } 6 \text { weeks; un- } \\
\text { compensated congestive heart failure; severe valvular disease; unstable angina. }\end{array}$
\end{tabular}

Interventions
PAC 1 group $(n=45)$ - transfer to ICU, PAC placed followed by "tune-up" treatment (using predefined
PAC 2 group $(n=23)$ - transfer to anaesthetic holding area, PAC placed followed by "tune-up" treat-
ment (using predefined end points) at least 3 hrs preoperatively.
Control group $(n=21)$ usual care without a PAC. Arterial catheters and CVCs placed.

Outcomes Main outcome cardiovascular complications. Secondary outcomes were immediate postoperative graft thrombosis and adverse intra-operative events. Also reported mortality (not specified), ICU LOS, hospital LOS.

\section{Notes}

\section{Risk of bias}

\begin{tabular}{|c|c|c|}
\hline Bias & Authors' judgement & Support for judgement \\
\hline $\begin{array}{l}\text { Random sequence genera- } \\
\text { tion (selection bias) }\end{array}$ & Low risk & Used random number generator (Statworks) \\
\hline $\begin{array}{l}\text { Allocation concealment } \\
\text { (selection bias) }\end{array}$ & Unclear risk & $\begin{array}{l}\text { Eligible patients were entered consecutively in order of the surgical schedule, } \\
\text { no central allocation used, anaesthesiologist may have foreseen allocation } \\
\text { while screening for eligibility }\end{array}$ \\
\hline $\begin{array}{l}\text { Blinding of participants } \\
\text { and personnel (perfor- } \\
\text { mance bias) } \\
\text { primary outcome }\end{array}$ & Unclear risk & Appears to be the study group treated the patients postoperatively \\
\hline $\begin{array}{l}\text { Blinding of outcome as- } \\
\text { sessment (detection bias) } \\
\text { primary outcome }\end{array}$ & Low risk & $\begin{array}{l}\text { Anesthesioloist cared for initial } 18 \text { hours and unlikely to influence LOS and } \\
\text { mortality }\end{array}$ \\
\hline $\begin{array}{l}\text { Incomplete outcome data } \\
\text { (attrition bias) } \\
\text { alloutcomes }\end{array}$ & Low risk & Reported all outcome data \\
\hline $\begin{array}{l}\text { Selective reporting (re- } \\
\text { porting bias) }\end{array}$ & Low risk & Reported all predefined outcome data \\
\hline Other bias & Low risk & None \\
\hline
\end{tabular}

Bender 1997

\begin{tabular}{ll}
\hline Methods & Randomized but methods not described. \\
\hline Participants & $\begin{array}{l}\text { Entry criteria: scheduled for elective infrarenal aortic reconstruction or lower limb revascularize (by a } \\
\text { single surgeon). Exclusion criteria: anticipated need before surgery for suprarenal or supra-coeliac aor- } \\
\text { tic clamping; myocardial infarction within } 3 \text { months or inadequately controlled angina; poorly com- }\end{array}$ \\
\hline
\end{tabular}


Bender 1997 (Continued)

pensated congestive heart failure; coronary artery bypass surgery within 6 weeks; symptomatic aortic/mitral valvular disease.

\begin{tabular}{ll}
\hline Interventions & PAC group $(n=51)$ - transfer to ICU, PAC placed followed by "optimizations" preoperatively using a \\
treatment algorithm. \\
Control group $(n=53)$ - standard care without a PAC. Arterial catheter and CVC placed.
\end{tabular}

ed.

Notes

\section{Risk of bias}

\begin{tabular}{|c|c|c|}
\hline Bias & Authors' judgement & Support for judgement \\
\hline $\begin{array}{l}\text { Random sequence genera- } \\
\text { tion (selection bias) }\end{array}$ & High risk & Patients were assigned randomly by the surgical intensivist \\
\hline $\begin{array}{l}\text { Allocation concealment } \\
\text { (selection bias) }\end{array}$ & High risk & Intensivist assigned patients, not concealed at all \\
\hline $\begin{array}{l}\text { Blinding of participants } \\
\text { and personnel (perfor- } \\
\text { mance bias) } \\
\text { primary outcome }\end{array}$ & High risk & Not blinded. Patients were chosen. \\
\hline $\begin{array}{l}\text { Blinding of outcome as- } \\
\text { sessment (detection bias) } \\
\text { primary outcome }\end{array}$ & High risk & $\begin{array}{l}\text { Same physician analysed data and cared for all patients, not blinded for any } \\
\text { outcome }\end{array}$ \\
\hline $\begin{array}{l}\text { Incomplete outcome data } \\
\text { (attrition bias) } \\
\text { alloutcomes }\end{array}$ & Unclear risk & Did not report about patients who did not get PAC postoperatively in group 2 \\
\hline $\begin{array}{l}\text { Selective reporting (re- } \\
\text { porting bias) }\end{array}$ & High risk & $\begin{array}{l}\text { Postoperative non-PA catheter group data is not reported and no tables or } \\
\text { number of patients }\end{array}$ \\
\hline Other bias & High risk & $\begin{array}{l}\text { One surgical intensivist cared for all } 104 \text { patients reported and the unreport- } \\
\text { ed group of patients for the LOS of } 27 \text { days at times reported is likely to create } \\
\text { several unknown bias }\end{array}$ \\
\hline
\end{tabular}

\section{Valentine 1998}

\begin{tabular}{ll}
\hline Methods & Randomized using sealed envelopes. No other details given. \\
\hline Participants & Entry criteria: \\
elective abdominal aortic reconstruction. \\
Exclusion criteria: \\
myocardial infarction within 3 months; coronary artery bypass surgery within 6 weeks; severe aor- \\
tic/mitral valve disease; unstable angina/recent change in angina symptoms; clinically overt congestive \\
cardiac failure; advanced chronic renal insufficiency; repeat aortic operations; additional procedures, \\
e.g. renal artery bypass grafting performed. \\
\hline
\end{tabular}

Interventions

PAC group ( $n=60$ ) - transfer to ICU, PAC placed followed by "tune-up" treatment (using predefined end points used be Berlauk et al) at least 14 hrs preoperatively. 
Valentine 1998 (Continued)

Control group $(n=60)$ not transferred to ICU, CVC placed and no specific preoperative treatment.

Outcomes Adverse postoperative events (defined), duration of ventilation,

ICU LOS and hospital LOS, hospital mortality.

Main outcome not stated.

Notes

\section{Risk of bias}

\begin{tabular}{|c|c|c|}
\hline Bias & Authors' judgement & Support for judgement \\
\hline $\begin{array}{l}\text { Random sequence genera- } \\
\text { tion (selection bias) }\end{array}$ & Low risk & Used sealed envelopes \\
\hline $\begin{array}{l}\text { Allocation concealment } \\
\text { (selection bias) }\end{array}$ & Unclear risk & Not mentioned how allocation was done \\
\hline $\begin{array}{l}\text { Blinding of participants } \\
\text { and personnel (perfor- } \\
\text { mance bias) } \\
\text { primary outcome }\end{array}$ & Unclear risk & Not mentioned if the study group also treated the patients \\
\hline $\begin{array}{l}\text { Blinding of outcome as- } \\
\text { sessment (detection bias) } \\
\text { primary outcome }\end{array}$ & Unclear risk & $\begin{array}{l}\text { Not mentioned study reviewers were blinded from knowing or altering the out- } \\
\text { come }\end{array}$ \\
\hline $\begin{array}{l}\text { Incomplete outcome data } \\
\text { (attrition bias) } \\
\text { alloutcomes }\end{array}$ & Low risk & Reported all predefined outcome data \\
\hline $\begin{array}{l}\text { Selective reporting (re- } \\
\text { porting bias) }\end{array}$ & Low risk & No selective reporting \\
\hline Other bias & Low risk & $\begin{array}{l}\text { Two control group patients were transferred over to PAC but did not include } \\
\text { them in analysis }\end{array}$ \\
\hline
\end{tabular}

Rhodes 2002

Methods Randomized using computer generated random numbers stored in sealed envelopes.

\begin{tabular}{ll}
\hline Participants & Entry criteria: \\
& either circulatory shock (definition given); oliguria (definition given); requirement for vasoactive infu- \\
& sion; need for mechanical ventilation. \\
& Exclusion criteria: \\
& less than 18 yrs of age; admitted to ICU for preoperative optimizations.
\end{tabular}

Interventions

PAC group ( $n=96)$ - PAC placed (no management protocol).

Control group $(n=105)$ - standard care without a PAC or any other form of cardiac output monitoring.

\begin{tabular}{ll}
\hline Outcomes & Main outcome 28-day mortality. \\
& Secondary outcomes ICU LOS, hospital LOS and morbidity.
\end{tabular}

Notes

\section{Risk of bias}


Rhodes 2002 (Continued)

\begin{tabular}{|c|c|c|}
\hline Bias & Authors' judgement & Support for judgement \\
\hline $\begin{array}{l}\text { Random sequence genera- } \\
\text { tion (selection bias) }\end{array}$ & Low risk & Quirk of computer generated sequence \\
\hline $\begin{array}{l}\text { Allocation concealment } \\
\text { (selection bias) }\end{array}$ & Low risk & Sealed envelopes \\
\hline $\begin{array}{l}\text { Blinding of participants } \\
\text { and personnel (perfor- } \\
\text { mance bias) } \\
\text { primary outcome }\end{array}$ & Low risk & $\begin{array}{l}\text { Double blinding of the study was not feasible, but treating physicians were not } \\
\text { prelocalized to follow a path, allowed to treat clinically and remove PAC if felt } \\
\text { the need does not exist, less likely to influence the outcome }\end{array}$ \\
\hline $\begin{array}{l}\text { Blinding of outcome as- } \\
\text { sessment (detection bias) } \\
\text { primary outcome }\end{array}$ & Low risk & $\begin{array}{l}\text { Study outcome assessment was done later on and treating physicians were } \\
\text { not given instructions to follow a protocol and end result }\end{array}$ \\
\hline $\begin{array}{l}\text { Incomplete outcome data } \\
\text { (attrition bias) } \\
\text { alloutcomes }\end{array}$ & Low risk & $\begin{array}{l}\text { All data are reported including the PAC group who did not get the catheter, in- } \\
\text { cluded in the analysis }\end{array}$ \\
\hline $\begin{array}{l}\text { Selective reporting (re- } \\
\text { porting bias) }\end{array}$ & Low risk & None \\
\hline Other bias & Low risk & Well covered without any bias \\
\hline
\end{tabular}

Richard 2003

\begin{tabular}{|c|c|}
\hline Methods & Randomized using 24-hour, 7 day-a-week, central telephone service. \\
\hline Participants & $\begin{array}{l}\text { Entry criteria: } \\
\text { circulatory shock (definition given) for less than } 12 \text { hours and/or acute respiratory distress syndrome } \\
\text { (definition given) for more than } 24 \text { hours. } \\
\text { Exclusion criteria: } \\
\text { less than } 18 \text { years; haemorrhagic shock; myocardial infarction complicated by cardiogenic shock; } \\
\text { thrombocytopaenia (platelets }<10,000 \mathrm{~mm}-3 \text { ); participated in other trials in the last } 30 \text { days; were mori- } \\
\text { bund; physician refused to agree with use of full life support. }\end{array}$ \\
\hline Interventions & $\begin{array}{l}\text { PAC group }(n=335) \text { - PAC placed (no management protocol). } \\
\text { Control group }(n=341) \text { - standard care without a PAC. }\end{array}$ \\
\hline Outcomes & $\begin{array}{l}\text { Main outcome } 28 \text {-day mortality. } \\
\text { Secondary outcomes 14-day mortality, } \\
90 \text {-day mortality, } \\
\text { ICU LOS, hospital LOS. }\end{array}$ \\
\hline
\end{tabular}

Notes

\section{Risk of bias}

\begin{tabular}{lll}
\hline Bias & Authors' judgement & Support for judgement \\
\hline $\begin{array}{l}\text { Random sequence genera- } \\
\text { tion (selection bias) }\end{array}$ & Low risk & Permuted block algorithm with stratification of each centre \\
\hline
\end{tabular}


Richard 2003 (Continued)

\begin{tabular}{|c|c|c|}
\hline $\begin{array}{l}\text { Allocation concealment } \\
\text { (selection bias) }\end{array}$ & Low risk & Central randomizations by telephone 24 hours a day 7 days a week \\
\hline $\begin{array}{l}\text { Blinding of participants } \\
\text { and personnel (perfor- } \\
\text { mance bias) } \\
\text { primary outcome }\end{array}$ & Low risk & No standardized protocols and analysis was not done by treating physicians \\
\hline $\begin{array}{l}\text { Blinding of outcome as- } \\
\text { sessment (detection bias) } \\
\text { primary outcome }\end{array}$ & Low risk & $\begin{array}{l}\text { Outcome assessment was blinded to study personal and unbinding of others is } \\
\text { not likely to induce bias, multi-entered nature }\end{array}$ \\
\hline $\begin{array}{l}\text { Incomplete outcome data } \\
\text { (attrition bias) } \\
\text { alloutcomes }\end{array}$ & Low risk & None missing \\
\hline $\begin{array}{l}\text { Selective reporting (re- } \\
\text { porting bias) }\end{array}$ & Low risk & Reported specifically \\
\hline Other bias & Low risk & None \\
\hline
\end{tabular}

\section{Sandham 2003}

\begin{tabular}{ll}
\hline Methods & Randomized using computer generated sequence concealed in sealed, opaque consecutively num- \\
bered envelopes. Stratified according to type of surgery, ASA class and blocked according to centre.
\end{tabular}

\begin{tabular}{ll}
\hline Participants & Entry criteria: \\
& Age $>60 ;$ American Society of Anesthesiologists class III or IV risk; scheduled for urgent/elective major \\
abdominal, thoracic, vascular or orthopaedic surgery. & Exclusion criteria: none stated.
\end{tabular}

\begin{tabular}{ll}
\hline Interventions & PAC group $(n=997)$ - PAC placed prior to surgery, followed by treatment directed to predefined physio- \\
& logical goals. \\
& Control group $(n=997)$ - standard care without a PAC. Placement of CVC permitted.
\end{tabular}

\begin{tabular}{ll}
\hline Outcomes Main outcome hospital mortality. Secondary outcome hospital LOS. \\
\hline Notes
\end{tabular}

\begin{tabular}{lll}
\hline Risk of bias & \\
\hline Bias & Authors' judgement & Support for judgement \\
\hline $\begin{array}{l}\text { Random sequence genera- } \\
\text { tion (selection bias) }\end{array}$ & Low risk & Computer generated sequence \\
\hline $\begin{array}{l}\text { Allocation concealment } \\
\text { (selection bias) }\end{array}$ & Low risk & Sealed envelopes used \\
\hline $\begin{array}{l}\text { Blinding of participants } \\
\text { and personnel (perfor- } \\
\text { mance bias) } \\
\text { primary outcome }\end{array}$ & Low risk & $\begin{array}{l}\text { Single blind, not double, not feasible but large multicentre trial unlikely to in- } \\
\text { troduce bias }\end{array}$ \\
\hline $\begin{array}{l}\text { Blinding of outcome as- } \\
\text { sessment (detection bias) }\end{array}$ & Low risk & Blinded assessment of outcome done \\
\hline
\end{tabular}


Sandham 2003 (Continued) primary outcome

\begin{tabular}{lll}
\hline $\begin{array}{l}\text { Incomplete outcome data } \\
\text { (attrition bias) } \\
\text { alloutcomes }\end{array}$ & Low risk & None \\
\hline $\begin{array}{l}\text { Selective reporting (re- } \\
\text { porting bias) }\end{array}$ & Low risk & Well reported \\
\hline Other bias & Low risk & None \\
\hline
\end{tabular}

\section{Harvey 2005}

Methods $\quad$ Randomized using a 24-hour, 7 day-a-week, central telephone randomization service and minimized by
unit, age group, presumptive clinical syndrome, surgical status.

$\begin{array}{ll}\text { Participants } & \text { Entry criteria: deemed to require management with a PAC by the treating clinician. } \\ & \text { Exclusion criteria: less than } 16 \text { years; admitted electively for preoperative optimizations; PAC already in } \\ & \text { situ on admission to ICU; previously enrolled into the trial; declared brain dead with PAC placed prior to } \\ \text { organ donation. }\end{array}$

PAC group $(n=506)$ - PAC placed (no management protocol).
Control $(n=508)$ - standard care without a PAC but with the option to use alternative cardiac output
monitoring devices if the unit had opted to be in stratum $B$.

\begin{tabular}{ll}
\hline Outcomes & Primary outcome hospital mortality. Secondary outcomes ICU LOS, hospital LOS, organ-days of sup- \\
port in ICU, costs of care.
\end{tabular}

\section{Notes}

\section{Risk of bias}

\begin{tabular}{|c|c|c|}
\hline Bias & Authors' judgement & Support for judgement \\
\hline $\begin{array}{l}\text { Random sequence genera- } \\
\text { tion (selection bias) }\end{array}$ & Low risk & Minimization was described \\
\hline $\begin{array}{l}\text { Allocation concealment } \\
\text { (selection bias) }\end{array}$ & Low risk & Used a central 24 hour telephone service \\
\hline $\begin{array}{l}\text { Blinding of participants } \\
\text { and personnel (perfor- } \\
\text { mance bias) } \\
\text { primary outcome }\end{array}$ & Low risk & $\begin{array}{l}\text { Not blinded, not likely influence the results due to multicentre trial and inves- } \\
\text { tigators are not providers }\end{array}$ \\
\hline $\begin{array}{l}\text { Blinding of outcome as- } \\
\text { sessment (detection bias) } \\
\text { primary outcome }\end{array}$ & Low risk & Investigators were blinded \\
\hline $\begin{array}{l}\text { Incomplete outcome data } \\
\text { (attrition bias) } \\
\text { alloutcomes }\end{array}$ & Low risk & None \\
\hline $\begin{array}{l}\text { Selective reporting (re- } \\
\text { porting bias) }\end{array}$ & Low risk & None \\
\hline
\end{tabular}


Harvey 2005 (Continued)
Other bias
Low risk
None

\section{NHLBI 2006}

Methods

Randomized multicentre factorial study, patients with acute lung injury for 48 hours or less, randomly assigned in permuted blocks of eight to receive a PAC or a CVC with the use of an automated system.

Patients were simultaneously randomly assigned to a strategy of either liberal or conservative use of fluids guided by a protocol.

\section{Participants \\ Inclusion criteria: patients receiving positive pressure ventilation by tracheal tube and had a ratio of the partial pressure of arterial oxygen $\left(\mathrm{PaO}_{2}\right)$ to the fraction of inspired oxygen $\left(\mathrm{FiO}_{2}\right)$ below 300 and bi- lateral infiltrates on chest radiography consistent with the presence of pulmonary edema not due to left atrial hypertension. \\ Exclusion criteria: presence of a PA catheter after the onset of acute lung injury, presence of acute lung injury for more than 48 hours, inability to obtain consent, presence of chronic conditions that could in- dependently impair survival or weaning or compliance with protocol such as dialysis, severe lung or neuromuscular disease, irreversible conditions and estimated six month mortality rate exceeded $50 \%$ such as cancer.}

Interventions

All patients received low tidal volume ventilation according to ARDS network protocol within one hour after randomizations and continued until day 28 or until breathing without assistance.

PAC or CVC was inserted within 4 hours after randomizations. Haemodynamic management as dictated by the protocol was started within the next 2 hours and continued for 7 days or until 12 hours after the patient was able to breathe without assistance. PAC was allowed to be replaced by a CVC if haemodynamic stability defined by the absence of protocol directed interventions for $>$ than 24 hours was achieved after day 3 .

Outcomes

Four main protocol variables were measured. Blood pressure and urinary output guided management was in both groups. PAOP and $\mathrm{Cl}$ in the PAC group and CVP and clinical assessment (skin temperature and appearance, rate of capillary refilling) in the CVC group guided management. Outcome measures were reversal of hypotension, oliguria and ineffective circulation. Fluid therapy either crystalloids or colloids and vasopressors were used as per the judgement of the physician, but weaning from vasopressors was done as per protocol.

\section{Risk of bias}

\begin{tabular}{lll}
\hline Bias & Authors' judgement & Support for judgement \\
\hline $\begin{array}{l}\text { Random sequence genera- } \\
\text { tion (selection bias) }\end{array}$ & Low risk & Used an automated system in permuted blocks of eight \\
\hline $\begin{array}{l}\text { Allocation concealment } \\
\text { (selection bias) }\end{array}$ & Unclear risk & Not mentioned \\
\hline $\begin{array}{l}\text { Blinding of participants } \\
\begin{array}{l}\text { and personnel (perfor- } \\
\text { mance bias) } \\
\text { primary outcome }\end{array}\end{array}$ & High risk & Not blinded \\
\hline
\end{tabular}

Blinding of outcome as-

High risk

Not blinded

sessment (detection bias) 
NHLBI 2006 (Continued) primary outcome

\begin{tabular}{lll}
\hline $\begin{array}{l}\text { Incomplete outcome data } \\
\text { (attrition bias) } \\
\text { alloutcomes }\end{array}$ & Low risk & Only one lost to follow-up in control group \\
\hline $\begin{array}{l}\text { Selective reporting (re- } \\
\text { porting bias) }\end{array}$ & Low risk & Published reports included all outcomes \\
\hline Other bias & High risk & $\begin{array}{l}\text { Two different randomizations were done simultaneously (conservative and lib- } \\
\text { eral fluid therapy and PAC versus CVC) }\end{array}$ \\
\hline
\end{tabular}

PAC - pulmonary artery catheter

CVC - central venous catheter

CVP - central venous pressure

LOS - length of stay

ICU - intensive care unit

FACTT - Fluid And Catheter Treatment Trial

Characteristics of excluded studies [ordered by study ID]

\begin{tabular}{|c|c|}
\hline Study & Reason for exclusion \\
\hline Bach 1992 & Not an RCT of management with PAC compared with management without a PAC \\
\hline Barone 2001 & Review and meta-analysis \\
\hline Boldt 1995 & Not an RCT of management with PAC compared with management without a PAC \\
\hline Bonazzi 2002 & Patients assigned to the control group were not transferred to ICU of HDU following surgery \\
\hline Boyd 1993 & Not an RCT of management with PAC compared with management without a PAC \\
\hline Brazzi 1995 & Not an RCT of management with PAC compared with management without a PAC \\
\hline Cobb 1992 & Not an RCT of management with PAC compared with management without a PAC \\
\hline Cohen 1998 & Not an RCT of management with PAC compared with management without a PAC \\
\hline Eyer 1990 & Not an RCT of management with PAC compared with management without a PAC \\
\hline Girbes 1999 & Study end point was the commencement of surgery \\
\hline Holmes 1997 & Not an RCT \\
\hline Kearns 1993 & Summary of a previously reported RCT \\
\hline Latour-Perez 1997 & Not an RCT \\
\hline Mermel 1991 & Not an RCT \\
\hline Mitchell 1992 & Not an RCT of management with PAC compared with management without a PAC \\
\hline Orlando 1985 & Conference abstract only \\
\hline
\end{tabular}




\begin{tabular}{|c|c|}
\hline Study & Reason for exclusion \\
\hline Raybin 1989 & Letter \\
\hline Schultz 1985 & Not all patients assigned to the control group were transferred to ICU or HDU following surgery \\
\hline Senagore 1987 & Not an RCT of management with a PAC compared with management without PAC \\
\hline Shoemaker 1990 & $\begin{array}{l}\text { Patients were randomly allocated in the second part of the study only. In addition, there was no } \\
\text { clear data on mortality in the two groups }\end{array}$ \\
\hline Sola 1993 & Review article \\
\hline Stewart 1998 & Not an RCT \\
\hline Stout 2006 & $\begin{array}{l}\text { Randomized part of this trial is to be cardiac output (CO) (indocyanine green (ICG)) or not and } \\
\text { didn't include PACs. PACs and CO (TD) are only referred to in the literature review part of the study }\end{array}$ \\
\hline Stubbig 1992 & Not an RCT of management with PAC compared with management without a PAC \\
\hline Suttner 2006 & Not an RCT, PAC compared with thoracic electrical bioimpedance, non-invasive method \\
\hline Takala 2011 & $\begin{array}{l}\text { Not an RCT of use of PACs - both groups had some use of PAC, the randomization was to MICO or } \\
\text { not }\end{array}$ \\
\hline Tuman 1989 & Not an RCT \\
\hline Wilson 1999 & Not all patients assigned to the control group were transferred to ICU or HDU following surgery \\
\hline Yu 1993 & Not an RCT of management with PAC compared with management without a PAC \\
\hline Yu 1995 & Not an RCT of management with PAC compared with management without a PAC \\
\hline Yu 2011 & Tested the intervention of blood volume measurement and both groups had PACs \\
\hline Ziegler 1997 & Not an RCT of management with PAC compared with management without a PAC \\
\hline
\end{tabular}

ICU - intensive care unit

HDU - high dependency unit

MICO - minimally invasive cardiac output

PAC - pulmonary artery catheter

RCT - randomized controlled trial

\section{DATA AND ANALYSES}

\section{Comparison 1. Combined mortality: PAC versus no PAC}

\begin{tabular}{lllll}
\hline Outcome or subgroup title & No. of studies & $\begin{array}{l}\text { No. of partici- } \\
\text { pants }\end{array}$ & Statistical method & Effect size \\
\hline 1 Combined mortality of all studies & 13 & 5686 & $\begin{array}{l}\text { Risk Ratio (M-H, Random, } \\
95 \% \mathrm{Cl})\end{array}$ & $1.01[0.95,1.08]$ \\
\hline
\end{tabular}


Analysis 1.1. Comparison 1 Combined mortality: PAC versus no PAC, Outcome 1 Combined mortality of all studies.

\begin{tabular}{|c|c|c|c|c|c|}
\hline Study or subgroup & $\begin{array}{l}\text { PAC } \\
n / N\end{array}$ & $\begin{array}{c}\text { Control } \\
n / N\end{array}$ & $\begin{array}{c}\text { Risk Ratio } \\
\text { M-H, Random, } 95 \% \mathrm{Cl}\end{array}$ & Weight & $\begin{array}{c}\text { Risk Ratio } \\
\text { M-H, Random, 95\% Cl }\end{array}$ \\
\hline Bender 1997 & $1 / 51$ & $1 / 53$ & 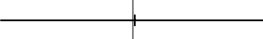 & $0.05 \%$ & $1.04[0.07,16.18]$ \\
\hline Berlauk 1991 & $1 / 68$ & $2 / 21$ & - & $0.07 \%$ & $0.15[0.01,1.62]$ \\
\hline Guyatt 1991 & $10 / 16$ & $9 / 17$ & 1 & $1.14 \%$ & $1.18[0.66,2.12]$ \\
\hline Harvey 2005 & $346 / 506$ & $337 / 507$ & & $53.57 \%$ & $1.03[0.94,1.12]$ \\
\hline Isaacson 1990 & $1 / 49$ & $0 / 53$ & & $0.04 \%$ & $3.24[0.14,77.71]$ \\
\hline Joyce 1990 & $0 / 21$ & $0 / 19$ & & & Not estimable \\
\hline NHLBI 2006 & $140 / 513$ & $128 / 487$ & 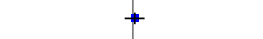 & $9.34 \%$ & $1.04[0.85,1.27]$ \\
\hline Pearson 1989 & $1 / 152$ & $1 / 74$ & & $0.05 \%$ & $0.49[0.03,7.68]$ \\
\hline Rhodes 2002 & $46 / 96$ & $50 / 105$ & + & $4.69 \%$ & $1.01[0.75,1.34]$ \\
\hline Richard 2003 & $199 / 335$ & $208 / 341$ & 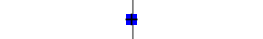 & $26.12 \%$ & $0.97[0.86,1.1]$ \\
\hline Sandham 2003 & $78 / 997$ & $77 / 997$ & + & $4.3 \%$ & $1.01[0.75,1.37]$ \\
\hline Shoemaker 1988 & $11 / 58$ & $7 / 30$ & $\rightarrow$ & $0.56 \%$ & $0.81[0.35,1.88]$ \\
\hline Total $(95 \% \mathrm{Cl})$ & 2922 & 2764 & 1 & $100 \%$ & $1.01[0.95,1.08]$ \\
\hline \multicolumn{6}{|c|}{ Total events: 837 (PAC), 821 (Control) } \\
\hline \multicolumn{6}{|c|}{ Heterogeneity: $\mathrm{Tau}^{2}=0 ; \mathrm{Chi}^{2}=5.26, \mathrm{df}=11(\mathrm{P}=0.92) ; \mathrm{I}^{2}=0 \%$} \\
\hline \multicolumn{6}{|c|}{ Test for overall effect: $Z=0.41(P=0.68)$} \\
\hline
\end{tabular}

\section{Comparison 2. PAC versus no PAC}

\begin{tabular}{lllll}
\hline Outcome or subgroup title & No. of studies & $\begin{array}{l}\text { No. of partici- } \\
\text { pants }\end{array}$ & Statistical method & Effect size \\
\hline $\begin{array}{l}1 \text { All types mortality (general intensive care } \\
\text { patients) }\end{array}$ & 5 & 2923 & $\begin{array}{l}\text { Risk Ratio (M-H, Ran- } \\
\text { dom, 95\% Cl) }\end{array}$ & $1.02[0.96,1.09]$ \\
\hline $\begin{array}{l}2 \text { All types mortality (high-risk surgical pa- } \\
\text { tients) }\end{array}$ & 8 & 2763 & $\begin{array}{l}\text { Risk Ratio (M-H, Ran- } \\
\text { dom, 95\% Cl) }\end{array}$ & $0.98[0.74,1.29]$ \\
\hline $\begin{array}{l}\text { 2.1 All types mortality (studies of periopera- } \\
\text { tive monitoring including pre-operative op- } \\
\text { timization) }\end{array}$ & 5 & 2395 & $\begin{array}{l}\text { Risk Ratio (M-H, Ran- } \\
\text { dom, 95\% Cl) }\end{array}$ & $0.98[0.74,1.29]$ \\
\hline $\begin{array}{l}2.2 \text { All types mortality (studies of periopera- } \\
\text { tive monitoring) }\end{array}$ & 3 & 368 & $\begin{array}{l}\text { Risk Ratio (M-H, Ran- } \\
\text { dom, 95\% Cl) }\end{array}$ & $1.10[0.14,8.82]$ \\
\hline
\end{tabular}

\section{Analysis 2.1. Comparison 2 PAC versus no PAC, Outcome 1 All types mortality (general intensive care patients).}

\begin{tabular}{|c|c|c|c|c|c|}
\hline Study or subgroup & $\begin{array}{c}\text { Treatment } \\
\mathrm{n} / \mathrm{N} \\
\end{array}$ & $\begin{array}{c}\text { Control } \\
n / N\end{array}$ & $\begin{array}{c}\text { Risk Ratio } \\
\text { M-H, Random, } 95 \% \text { CI }\end{array}$ & Weight & $\begin{array}{c}\text { Risk Ratio } \\
\text { M-H, Random, } 95 \% \mathrm{CI}\end{array}$ \\
\hline Guyatt 1991 & $10 / 16$ & $9 / 17$ & 1 & $1.21 \%$ & $1.18[0.66,2.12]$ \\
\hline Harvey 2005 & $346 / 506$ & $333 / 507$ & 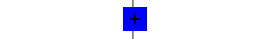 & $56.02 \%$ & $1.04[0.95,1.14]$ \\
\hline NHLBI 2006 & $140 / 513$ & $128 / 487$ & + & $9.95 \%$ & $1.04[0.85,1.27]$ \\
\hline
\end{tabular}




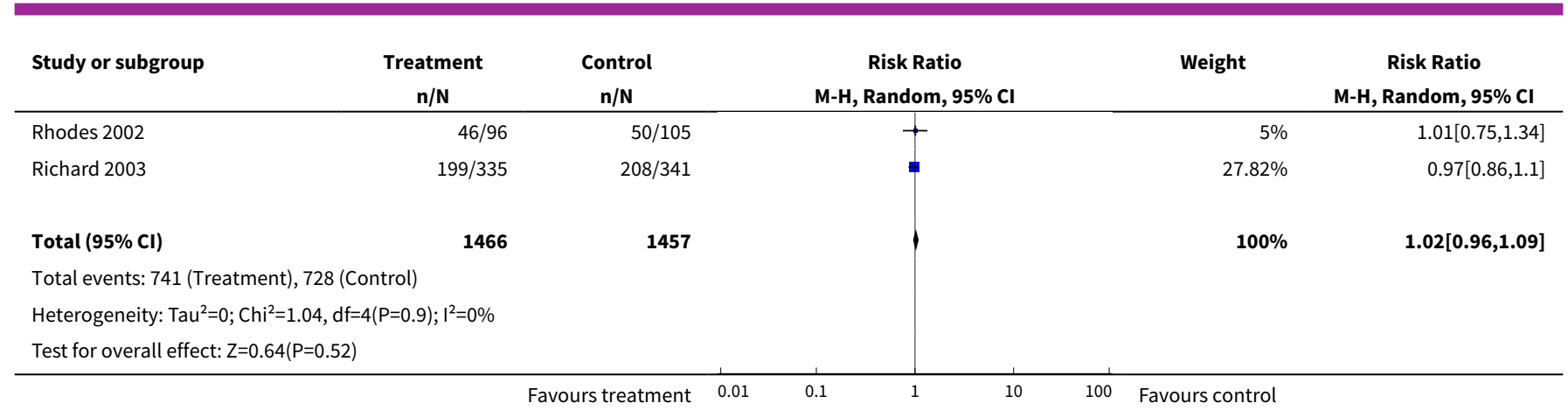

\section{Analysis 2.2. Comparison 2 PAC versus no PAC, Outcome 2 All types mortality (high-risk surgical patients).}

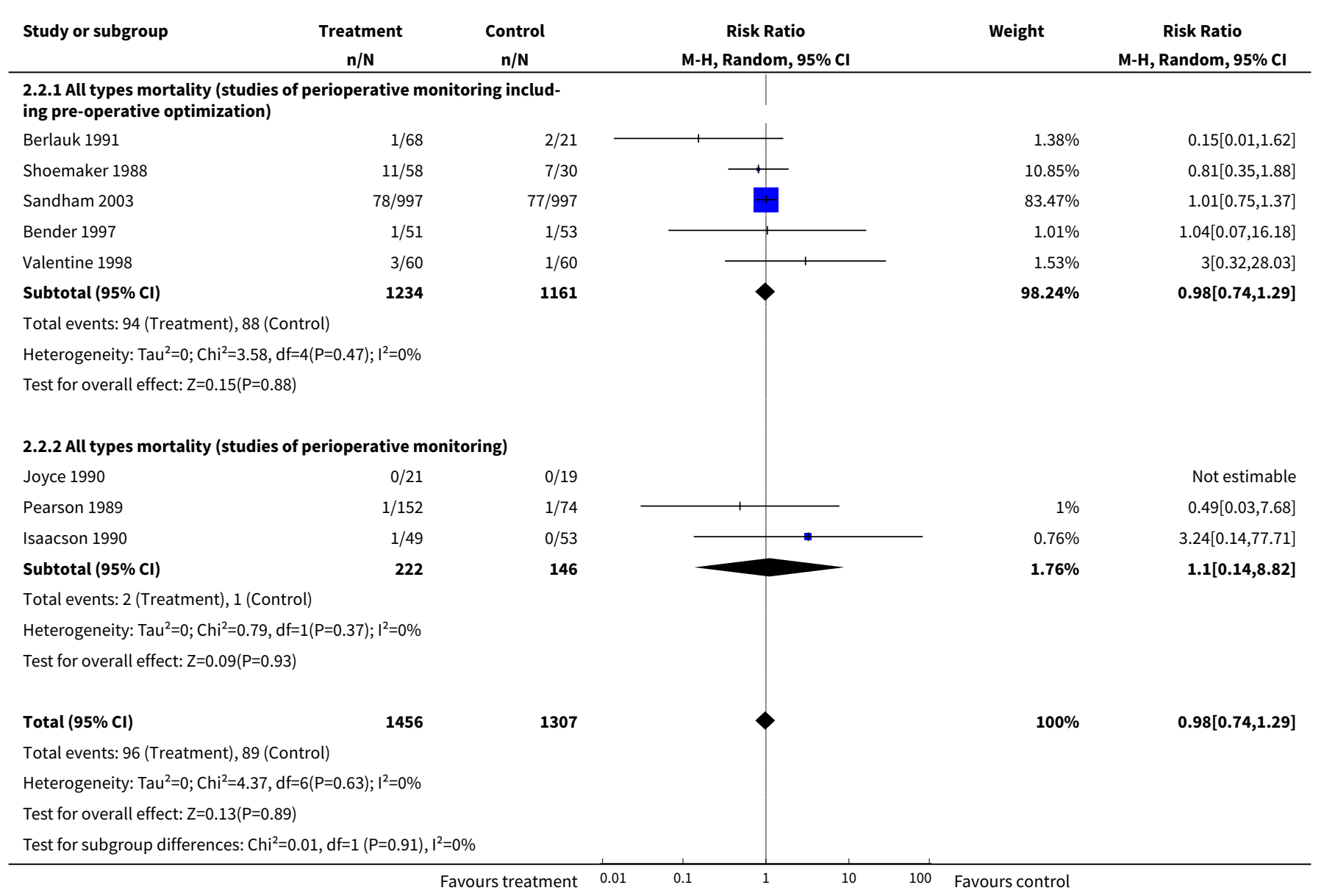

\section{Comparison 3. ICU length of stay PAC versus no PAC}

\begin{tabular}{lllll}
\hline Outcome or subgroup title & No. of studies & $\begin{array}{l}\text { No. of partici- } \\
\text { pants }\end{array}$ & Statistical method & Effect size \\
\hline $\begin{array}{l}1 \text { ICU length of stay (general intensive } \\
\text { care patients) }\end{array}$ & 4 & 2723 & $\begin{array}{l}\text { Mean Difference (IV, Ran- } \\
\text { dom, 95\% Cl) }\end{array}$ & $0.15[-0.74,1.03]$ \\
\hline
\end{tabular}

Pulmonary artery catheters for adult patients in intensive care (Review) 
Analysis 3.1. Comparison 3 ICU length of stay PAC versus no PAC, Outcome 1 ICU length of stay (general intensive care patients).

\begin{tabular}{|c|c|c|c|c|c|c|c|}
\hline \multirow[t]{2}{*}{ Study or subgroup } & \multicolumn{2}{|c|}{ Treatment } & \multicolumn{2}{|c|}{ Control } & \multirow{2}{*}{$\begin{array}{l}\text { Mean Difference } \\
\text { Random, } 95 \% \mathrm{Cl}\end{array}$} & \multirow[t]{2}{*}{ Weight } & \multirow{2}{*}{$\begin{array}{l}\text { Mean Difference } \\
\text { Random, } 95 \% \mathrm{CI}\end{array}$} \\
\hline & $\mathbf{N}$ & Mean(SD) & $\mathbf{N}$ & Mean(SD) & & & \\
\hline Guyatt 1991 & 16 & $10.3(0)$ & 17 & $8.1(0)$ & & & Not estimable \\
\hline Harvey 2005 & 506 & $10.7(16.1)$ & 508 & $10.7(20.1)$ & & $15.67 \%$ & $0[-2.24,2.24]$ \\
\hline NHLBI 2006 & 513 & $12.5(11.3)$ & 487 & $12(8.8)$ & - & $50.04 \%$ & $0.5[-0.75,1.75]$ \\
\hline Richard 2003 & 335 & $11.6(10.1)$ & 341 & $11.9(10)$ & $\mp$ & $34.28 \%$ & $-0.3[-1.82,1.22]$ \\
\hline \multicolumn{8}{|c|}{ Heterogeneity: $\operatorname{Tau}^{2}=0 ; \mathrm{Chi}^{2}=0.66, \mathrm{df}=2(\mathrm{P}=0.72) ; \mathrm{I}^{2}=0 \%$} \\
\hline \multicolumn{3}{|c|}{ Test for overall effect: $\mathrm{Z}=0.33(\mathrm{P}=0.74)$} & & & & & \\
\hline
\end{tabular}

Comparison 4. Hospital length of stay: PAC versus no PAC

\begin{tabular}{lllll}
\hline Outcome or subgroup title & No. of studies & $\begin{array}{l}\text { No. of partici- } \\
\text { pants }\end{array}$ & Statistical method & Effect size \\
\hline $\begin{array}{l}1 \text { Hospital length of stay (general inten- } \\
\text { sive care patients) }\end{array}$ & 2 & 1689 & $\begin{array}{l}\text { Mean Difference (IV, Ran- } \\
\text { dom, 95\% Cl) }\end{array}$ & $-0.80[-2.71,1.12]$ \\
\hline $\begin{array}{l}2 \text { Hospital length of stay (high-risk surgi- } \\
\text { cal patients) }\end{array}$ & 5 & 503 & $\begin{array}{l}\text { Mean Difference (IV, Ran- } \\
\text { dom, 95\% Cl) }\end{array}$ & $0.35[-0.05,0.75]$ \\
\hline
\end{tabular}

Analysis 4.1. Comparison 4 Hospital length of stay: PAC versus no PAC, Outcome 1 Hospital length of stay (general intensive care patients).

\begin{tabular}{|c|c|c|c|c|c|c|c|}
\hline \multirow{3}{*}{$\begin{array}{l}\text { Study or subgroup } \\
\text { Harvey } 2005\end{array}$} & \multicolumn{2}{|c|}{ Treatment } & \multicolumn{2}{|c|}{ Control } & \multirow{2}{*}{$\begin{array}{l}\text { Mean Difference } \\
\text { Random, } 95 \% \mathrm{Cl}\end{array}$} & \multirow[t]{2}{*}{ Weight } & \multirow{2}{*}{$\begin{array}{l}\text { Mean Difference } \\
\text { Random, } 95 \% \mathrm{Cl}\end{array}$} \\
\hline & $\mathbf{N}$ & Mean(SD) & $\mathbf{N}$ & Mean(SD) & & & \\
\hline & 506 & $22.9(34.3)$ & 507 & $26.1(45.4)$ & $\longrightarrow$ & $14.19 \%$ & $-3.2[-8.15,1.75]$ \\
\hline Richard 2003 & 335 & $14(11.6)$ & 341 & $14.4(11.3)$ & & $85.81 \%$ & $-0.4[-2 \cdot 13,1.33]$ \\
\hline Total $\star \star \star ~$ & 841 & & 848 & & & $100 \%$ & $-0.8[-2.71,1.12]$ \\
\hline \multicolumn{8}{|c|}{ Heterogeneity: Tau $^{2}=0.34 ; \mathrm{Chi}^{2}=1.09, \mathrm{df}=1(\mathrm{P}=0.3) ; \mathrm{I}^{2}=8.59 \%$} \\
\hline
\end{tabular}

Analysis 4.2. Comparison 4 Hospital length of stay: PAC versus no PAC, Outcome 2 Hospital length of stay (high-risk surgical patients).

\begin{tabular}{|c|c|c|c|c|c|c|c|}
\hline \multirow[t]{2}{*}{ Study or subgroup } & \multicolumn{2}{|c|}{ Treatment } & \multicolumn{2}{|c|}{ Control } & \multirow{2}{*}{$\begin{array}{l}\text { Mean Difference } \\
\text { Random, } 95 \% \mathrm{CI}\end{array}$} & \multirow[t]{2}{*}{ Weight } & \multirow{2}{*}{$\begin{array}{l}\text { Mean Difference } \\
\text { Random, } 95 \% \mathrm{Cl}\end{array}$} \\
\hline & $\mathbf{N}$ & Mean(SD) & $\mathbf{N}$ & Mean(SD) & & & \\
\hline Bender 1997 & 51 & $12.5(1.4)$ & 53 & $12(1.3)$ & + & $58.9 \%$ & $0.5[-0.02,1.02]$ \\
\hline
\end{tabular}




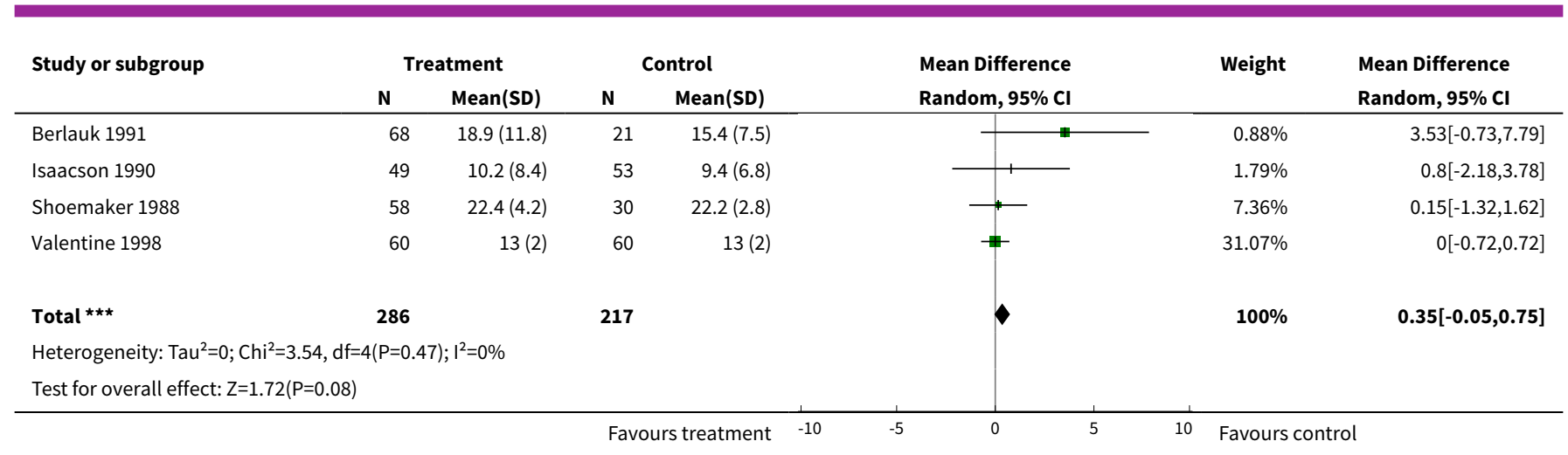

\section{Comparison 5. Cost of care: PAC versus no PAC}

\begin{tabular}{lllll}
\hline Outcome or subgroup title & No. of studies & $\begin{array}{l}\text { No. of partici- } \\
\text { pants }\end{array}$ & Statistical method & Effect size \\
\hline $\begin{array}{l}\text { 1 Cost of care (hospital charges, 1000's } \\
\text { of US dollars) }\end{array}$ & 2 & 191 & $\begin{array}{l}\text { Mean Difference (IV, Fixed, } \\
95 \% \text { CI) }\end{array}$ & $0.90[-2.62,4.42]$ \\
\hline
\end{tabular}

Analysis 5.1. Comparison 5 Cost of care: PAC versus no PAC, Outcome 1 Cost of care (hospital charges, 1000's of US dollars).

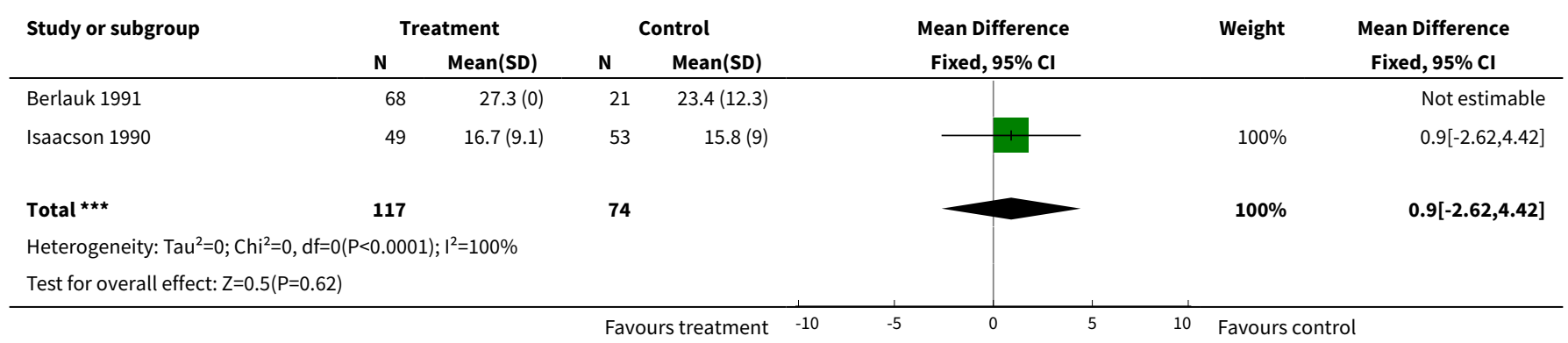

\section{APPENDICES}

\section{Appendix 1. Search strategy for CENTRAL, The Cochrane Library}

\#1 MeSH descriptor Catheterization, Swan-Ganz explode all trees

\#2 MeSH descriptor Heart Catheterization explode all trees

\#3 pulmonary artery catheter*

\#4 (pulmonary arter ${ }^{\star}$ ) near (flotation or cathet ${ }^{\star}$ )

\#5 (right heart) near catheter*

\#6 right-heart near catheter*

\#7 swan-ganz near catheter*

\#8 swanganz near catheter*

\#9 (\#1 OR \#2 OR \#3 OR \#4 OR \#5 OR \#6 OR \#7 OR \#8)

$\# 10 \mathrm{MeSH}$ descriptor Critical Care explode all trees

\#11 MeSH descriptor Intensive Care Units explode all trees

\#12 (intensiv* or critical or postanesthesia or postanaesthesia) near care 
\#13 high dependency unit*

\#14 (\#10 OR \#11 OR \#12 OR \#13)

\#15 (\#9 AND \#14)

\section{Appendix 2. Search strategy for MEDLINE (OvidSP)}

1. exp Catheterization-Swan-Ganz/ or Heart-Catheterization/ or pulmonary art?ery catheter. ti,ab. or (pulmonary arter ${ }^{\star}$ adj5 (flotation or cathet $\left.{ }^{\star}\right)$ ).mp. or (right?heart and catheter $\left.{ }^{\star}\right) \cdot m p$. or swan?ganz ${ }^{\star} . t i, a b$.

2. exp Critical care/ or exp Intensive-Care-Units/ or critical care unit*.mp. or ((intensiv or critical or post?an?esthesia) adj5 care unit).mp. or high dependency unit*.mp. or critical care.ti,ab.

3. 1 and 2

4. (adolescent ${ }^{\star}$ or child $^{\star}$ or preschool $^{\star}$ or infant $^{\star}$ or newborn).mp.

5. Adult.mp.

6.4 not $(5$ and 4$)$

7.3 not 6

8. ((randomised controlled trial or controlled clinical trial).pt. or randomized.ab. or placebo.ab. or drug therapy.fs. or randomly.ab. or trial.ab. or groups.ab.) not (animals not (humans and animals)).sh.

9.7 and 8

\section{Appendix 3. Search strategy for EMBASE (OvidSP)}

1. exp swan-ganz-catheter/ or exp heart-catheterization/ or pulmonary art?ery catheter.ti,ab. or (pulmonary arter* adj5 (flotation or cathet $\left.{ }^{\star}\right)$ ).mp. or (right?heart and catheter $\left.{ }^{\star}\right) \cdot m p$. or swan?ganz $z^{\star} . t i, a b .($

2 . exp intensive-care/ or critical care unit ${ }^{\star} . \mathrm{mp}$. or ((intensiv* ${ }^{\star}$ or critical or post?an?esthesia) adj5 care unit).mp. or high dependency unit*.mp. or critical care.ti,ab.

3.1 and 2

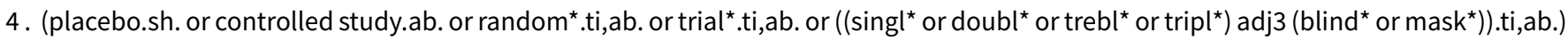
not (animals not (humans and animals)).sh.

5.3 and 4

\section{Appendix 4. Search strategy for CINAHL (EBSCOhost)}

S1 (MM "Swan-Ganz Catheterization")

S2 (MH "Heart Catheterization+")

S3 TX pulmonary arter* and TX ( flotation or cathet ${ }^{*}$ )

S4 TX ( swan-ganz or right-heart) and TX catheter*

$\mathrm{S} 5 \mathrm{~S} 1$ or S2 or S3 or S4

S6 (MH "Critical Care")

S7 (MM "Intensive Care Units")

S8 TX high dependency unit*

S9 AB ( intensiv* or critical or postanesthesia or postanaesthesia ) and AB care

S10 S6 or S7 or S8 or S9

S11 S5 and S10

\section{Appendix 5. Search strategy for grey literature}

Several combinations of the following search terms where used. Truncation was used when available.

pulmonary artery catheter

pulmonary arterial catheter

pulmonary artery catheterization

pulmonary arterial catheterization

right heart catheterization random

randomised

randomizations

randomised

randomizations

Pulmonary artery catheters for adult patients in intensive care (Review) 


\section{Grey Literature Sources}

www.nyam.org/library/pages/grey_literature_report

NYAM Grey Literature Collection

http://oaister.worldcat.org

OAlster - Digital Resource from Open Archive Collections

www.doaj.org

Directory of Open Access Journals

www.opendoar.org

OpenDOAR

\section{Clinical Trial Registers}

www.isrctn.org

Int Standard Randomized Controlled Trial Number Reg

https://www.clinicaltrialsregister.eu

Eur Clin Trials Register

(new 2011)

http://apps.who.int/trialsearch

WHO ICTRP

\section{Dissertations and Theses}

www.ndltd.org 
(Continued)

Networked Digital Library of Theses and Dissertations

ProQuest Dissertations \& Theses

\title{
Open Access Journals
}

www.doaj.org

Directory of Open Access Journals

www.opendoar.org

OpenDOAR

http://roar.eprints.org

Registry of Open Access Repositories

\section{Meeting Abstracts}

http://gateway.nlm.nih.gov/gw/Cmd

Meeting Abstracts thru NLM Gateway

Conference Abstracts (hand-searched in the original review)

European Society of Intensive Care Medicine

Intensive Care Medicine

http://xa.yimg.com/kq/groups/19299193/148298693/name/ISICEM+abstracts+2011.pdf

$31^{\text {st }}$ International Symposium on Intensive Care and Emergency medicine

\section{Society of Critical Care Medicine}

Critical Care Medicine

\author{
American Thoracic Society \\ The American Journal of Respiratory and Critical Care Medicine \\ Proceedings of the American Thoracic Society
}




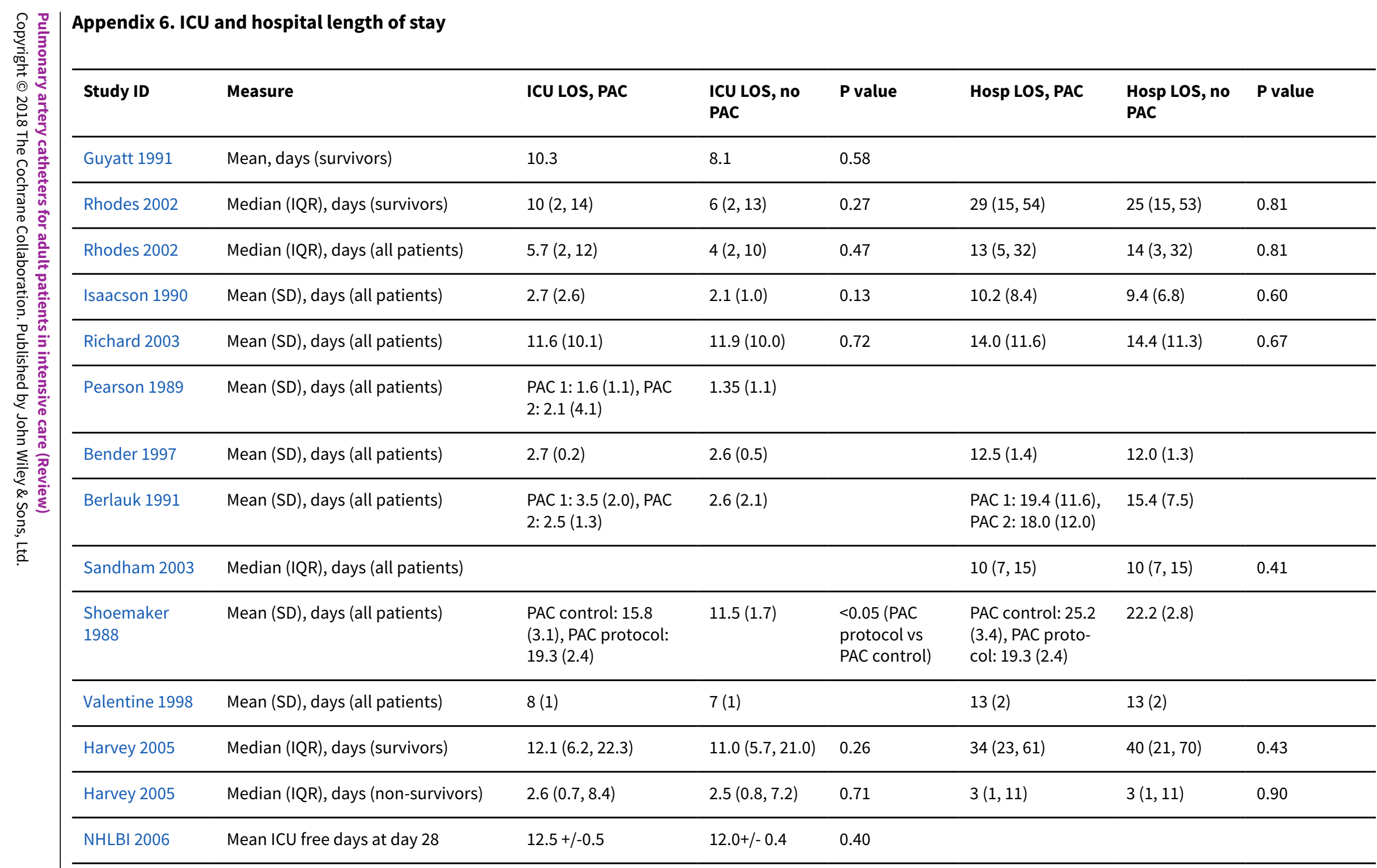




\section{Appendix 7. Costs of care}

\begin{tabular}{|c|c|c|c|c|c|}
\hline Study & Measure & Cost, PAC 1 & Cost, PAC 2 & Cost, no PAC & $P$ value \\
\hline Isaacson 1990 & $\begin{array}{l}\text { Mean (SD) total hospital charges per pa- } \\
\text { tient }\end{array}$ & $\$ 16,680(9,108)$ & $\mathrm{N} / \mathrm{A}$ & $\begin{array}{l}\$ 15,813 \\
(9,028)\end{array}$ & \\
\hline Isaacson 1990 & $\begin{array}{l}\text { Mean (SD) Anesthesiologists fee per pa- } \\
\text { tient }\end{array}$ & $\$ 1,739(225)$ & $\mathrm{N} / \mathrm{A}$ & $\$ 1,551(252)$ & 0.0001 \\
\hline Pearson 1989 & Mean (SD) total costs (billed to patient) & $\$ 855.51(231)$ & $\$ 1128.38(759)$ & $\$ 591.19(68)$ & \\
\hline Berlauk 1991 & Mean (SD) total hospital charges & $\begin{array}{l}\$ 29,102 \\
(13,207)\end{array}$ & $\begin{array}{l}\$ 23,770 \\
(12,418)\end{array}$ & $\begin{array}{l}\$ 23,386 \\
(12,303)\end{array}$ & \\
\hline $\begin{array}{l}\text { Shoemaker } \\
1988\end{array}$ & Average (not specified) hospital charges & $\begin{array}{l}\text { PAC control: } \\
\$ 37,335\end{array}$ & $\begin{array}{l}\text { PAC protocol: } \\
\$ 27,665\end{array}$ & $\$ 30,748$ & \\
\hline Stevens 2005 & $\begin{array}{l}\text { Mean (SEM) total cost per patient } \\
\text { (converted to US } \$ \text {, reported in UK } £ 18,612 \\
\text { for PAC and } £ 19,211 \text { for no, PAC Cochrane } \\
\text { cost converter) }\end{array}$ & $\begin{array}{l}\$ 28,677.97 \\
(1627.12)\end{array}$ & & $\begin{array}{l}\$ 29,600.92 \\
(1987.67)\end{array}$ & \\
\hline
\end{tabular}

WHAT'S NEW

\begin{tabular}{lll}
\hline Date & Event & Description \\
\hline 13 December 2018 & Amended & Editorial team changed to Cochrane Emergency and Critical Care \\
\hline
\end{tabular}

\section{H IST ORY}

Protocol first published: Issue 1, 2002

Review first published: Issue 3, 2006

\begin{tabular}{lll}
\hline Date & Event & Description \\
\hline 24 April 2012 & $\begin{array}{l}\text { New citation required and conclusions } \\
\text { have changed }\end{array}$ & $\begin{array}{l}\text { This review is an update of a previous Cochrane systematic re- } \\
\text { view (Harvey 2006) that included 12 RCTs. The previous authors } \\
\text { Harvey S, Young D, Brampton W, Cooper A, Doig GS, Sibbald W } \\
\text { and Rowan K decided not to update the review. }\end{array}$ \\
& $\begin{array}{l}\text { In this updated version, we found five new large trials and chose } \\
\text { to include one large trial which met our inclusion criteria (NHLBI }\end{array}$ \\
& $\begin{array}{l}\text { 2006). Additionally three RCTs were excluded due to a different } \\
\text { patient population and end points (Bonazzi 2002; ESCAPE 2005; } \\
\text { Schultz 1985). }\end{array}$ \\
& $\begin{array}{l}\text { In general our review reaches the same conclusions as Harvey } \\
\text { 2006. However, we included one large new trial (NHLBI 2006) and } \\
\text { thus have more precise estimates on hospital mortality. We ap- } \\
\text { plied several additional sensitivity and subgroup analyses which }\end{array}$ \\
\hline
\end{tabular}




\begin{tabular}{lll}
\hline Date & Event & Description \\
\hline & & $\begin{array}{l}\text { supported the overall results. We graded the quality of evidence } \\
\text { of our outcomes. In our discussion we have cited several addi- } \\
\text { tional studies which are both in agreement and disagreement } \\
\text { with our results. We have reported the review with several addi- } \\
\text { tional subheadings and background information. We modified } \\
\text { some of the conclusions. }\end{array}$ \\
& New search has been performed & $\begin{array}{l}\text { In the previous version (Harvey 2006) the databases were } \\
\text { searched until 2002. In this updated version, we reran the search- } \\
\text { es until 31 January 2012. We included risk of bias tables, graph } \\
\text { and summary graph, study flow diagram, funnel plot, grey litera- } \\
\text { ture appendix and summary of finding tables. We have extended } \\
\text { our search strategy to include additional electronic databases. }\end{array}$ \\
\hline 7 August 2008 & Amended & Contact details updated. \\
\hline 31 July 2008 & Amended & Minor edit to text \\
\hline
\end{tabular}

\section{CONTRIBUTIONS OF AUTHORS}

S Rajaram (SR): lead author on meta-analysis, reviewed the papers, coordinated the review, screened search results, extracted data, assessed risk of bias, conducted the analysis, entered data into RevMan, interpreted the data and drafted the full review, edited and critically revised the report.

N Desai (ND): author on meta-analysis, reviewed the papers, drafted the background, edited references in RevMan, added clinical and consumer perspective in discussion, created summary of finding table and critically revised the report.

M Gajera (MG): author on meta-analysis, reviewed the papers, screened search results and selected articles, assessed risk of bias, appraised quality of papers, selected references, provided clinical perspective, and critically revised the report.

A Kalra (AK): author on meta-analysis, reviewed the papers and drafted part of the background, edited discussion and critically revised the report.

S Cavanaugh (SC): author on meta-analysis, assisted with literature search, drafted the grey literature report, organized the retrieval of papers, screened retrieved papers against eligibility criteria, provided additional data about papers, screened data on unpublished studies and critically revised the report.

W Brampton (WB): author on meta-analysis, provided advice on retrieved papers eligibility, performed previous work that was the foundation of the current review and critically revised the report.

S Harvey (SH): author on meta-analysis, performed previous work that was the foundation of the current review and critically revised the report.

D Young (DY): author on meta-analysis, performed previous work that was the foundation of the current review and critically revised the report.

K Rowan (KR): author on meta-analysis, performed previous work that was the foundation of the current review.

\section{DECLARATIONS OF INTEREST}

S Harvey, K Rowan, D Young and W Brampton are authors on one of the citations included in the original review and update (Harvey 2005). All other authors: none known. 


\section{SOURCES OF SUPPORT}

\section{Internal sources}

- University of Oxford (Young), UK.

For original review (Harvey 2006)

- Gloucestershire Hospitals NHS Trust (Brampton), UK.

For original review (Harvey 2006)

\section{External sources}

- National Health Service Health Technology Assessment Programme (Project Number 97/08/03), UK.

For original review (Harvey 2006)

\section{DIFFERENCES BETWEEN PROTOCOLANDREVIEW}

None

\section{NOTES}

None

\section{N DEX TERMS}

\section{Medical Subject Headings (MeSH)}

*Length of Stay; Catheterization, Swan-Ganz [adverse effects] [economics] [ ${ }^{\star}$ mortality]; Cost-Benefit Analysis; Critical Care [economics] [ ${ }^{\star}$ methods]; Critical Illness [ ${ }^{\star}$ mortality]; Hospital Mortality; Intensive Care Units; Randomized Controlled Trials as Topic

\section{MeSH check words}

Adult; Humans 